\title{
ABECEDÁRIOS EM CIRCULAÇÃO: ENTRE DICIONÁRIOS, IMPRESSOS E CARTILHAS ESCOLARES
}

\author{
DOI: http://dx.doi.org/10.1590/2236-3459/67559
}

\author{
Maria Stephanou \\ Universidade Federal do Rio Grande do Sul, Brasil. \\ Mariana Venafre Pereira Souza \\ Escola Municipal de Ensino Fundamental Décio Martins Costa, Brasil.
}

$\cos 8$

\begin{abstract}
Resumo
Abecedários são artefatos culturais, em geral associados à história da escolarização. São invenções seculares na história da cultura escrita. Não podemos circunscrevê-los à escola ou à história da alfabetização. Circularam em diferentes contextos socioculturais e geográficos. Fizeram-se presentes em diversas práticas de difusão da escrita, de produção artística, registro de genealogias, ensino da leitura e da escrita, entre outros. No âmbito da história cultural e da história da cultura escrita, os abecedários tiveram uma importância que ainda está por compreender. Acompanhamos aqui momentos da historicidade deste artefato e, como parte de um inventário documental, observamos a presença/ausência de abecedários em diferentes cartilhas que integram o acervo Memória da Cartilha da Ufrgs.

Palavras-chave: abecedários, cartilhas, história da cultura escrita.
\end{abstract}

\section{ABECEDARIOS OUTSTANDING: BETWEEN DICTIONARY, PRINTED AND EDUCATIONAL BOOKLETS}

\begin{abstract}
Abecedarios are cultural artifacts, usually associated with the history of the school. They're secular inventions in history of the writing culture. We can't circumscribe them to school or to the history of literacy. They circulated in different socio-cultural and geographical contexts. They were present in a number of written dissemination practices of artistic production, genealogies record, teaching reading and writing, among others. In the context of cultural history and the history of the writing culture, abecedarios had an importance that is yet to understand. We follow here moments of the historicity of this artifact and as part of a documentary inventory, we observed the presence/absence of abecedarios in different booklets that comprise the Memória da Cartilha of Ufrgs.

Key-words: abecedarios, booklets, history of the written culture.
\end{abstract}

ก. 50

Set./dez., 2016

p. $297-325$ 


\section{ABECEDARIOS EN CIRCULACIÓN: ENTRE DICCIONARIO, IMPRESOS Y CARTILLAS DE LA ESCUELA}

\section{Resumen}

Abecedarios son artefactos culturales, en general asociados a la historia de la escolarización. Son invenciones seculares en la historia de la cultura escrita. No podemos circunscribirlos a la escuela o a la historia de la alfabetización. Circularon en distintos contextos socioculturales y geográficos. Se hicieron presentes en diversas prácticas de difusión de la escrita, de producción artística, registro de genealogéas, enseño de la lectura y de la escrita, entre otros. En el ámbito de la historia cultural y de la historia de la cultura escrita, los abecedarios han tenido una importancia que aún está por comprender. Acompañamos aquí momentos de la historicidad de este artefacto y como parte de un inventario documental, observamos la presencia/ausencia de abecedarios en distintas cartillas que integram el acervo Memória da Cartilha de la Ufrgs.

Palabras-clave: abecedarios, cartillas, historia de la cultura escrita.

\section{ABÉCÉDAIRES EN CIRCULATION: ENTRE DICTIONNAIRE, IMPRIMÉE ET LIVRETS PEDAGOGIQUES}

\section{Résumé}

Les abécédaires sont des artefacts culturels, généralement associés à l'histoire de l'école. Sont des inventions séculaires au sein de l'histoire de la culture écrit. Nous ne pouvons pas les circonscrire à l'école ou à l'histoire de l'alphabétisation. Ils ont fait circuler dans différents contextes socio-culturels et géographiques. Ils étaient présents dans les diverses pratiques de diffusion de l'écriture, dans la production artistique, les généalogies, les enseignements de la lecture et de l'écriture, entre autres. Dans le contexte de l'histoire culturelle et de l'histoire de la culture écrite les abécédaires avaient une importance qui est encore à comprendre. Nous suivons ici l'historicité de cet artefact dans le cadre d'un inventaire documentaire qui nous avons observé autour de la présence / absence des abécédaires dans différentes brochures qui composent la collection Memória da Cartilha, Ufrgs.

Mots-clé: abécédaires, livrets, histoire de la culture écrite. 


\section{Introdução}

ste estudo ${ }^{1}$ integra uma pesquisa mais ampla que busca acompanhar a circulação de abecedários, artefatos culturais que remontam às origens da cultura escrita e que, em geral, têm sido naturalizados como exclusivos da história da escolarização, ideia errônea que urge desconstruir com pesquisas que demonstrem sua presença em diversos contextos socioculturais. Como propõem Cucuzza e Pineau (2002, p. 13), é preciso produzir uma história social do ensino da leitura e da escrita em perspectiva interdisciplinar que não se esgote na mirada diacrônica da didática, tampouco nas miradas escolarizantes que reduzem diversas práticas sociais a meras práticas escolares. É este o investimento que fazemos na investigação mais ampla sobre história das práticas de leitura e escrita dos séculos 19 e 20, na qual inscrevemos o estudo dos abecedários.

Neste ensaio, nos detivemos num propósito bem delimitado: observar a presença/ausência de abecedários em uma diversidade de dicionários, livros e em uma cartilha em especial, bastante conhecida e que se intitula Queres Ler?, destinada à alfabetização inicial e que integra o Acervo Memória da Cartilha $^{2}$ da Biblioteca da Faculdade de Educação da Universidade Federal do Rio Grande do Sul.

Em outro estudo (Stephanou; Souza, 2013) nossa atenção voltou-se à compreensão dos princípios de didatização dos abecedários no interior de diversas cartilhas escolares, ou seja, a intencionalidade pedagógica dirigida ao ensino da leitura e/ou da escrita. Para tal, indagamos o modo como os abecedários se inscreviam no suporte cartilha: como as letras do alfabeto se apresentam (tamanhos, formatos, tipos, ordenamentos); se constam imagens associadas a letras; se as letras aparecem sozinhas ou se formam sílabas, palavras, frases ou pequenos textos; quais são os universos temáticos das imagens que figuram nos abecedários; quais as finalidades dos abecedários, se mais voltados ao ensino da escrita, da leitura ou para ambas; se há associação de grafemas com fonemas; onde, topograficamente, se inscrevem nas cartilhas (início, meio, fim).

A análise dos abecedários inspira-se em estudos da história da cultura escrita, sob o olhar da história cultural. Concebemos, a partir de Viñao Frago (2008), que não existe um objeto que possa ser o mesmo visto de diversos lugares, ou seja, perspectivas diferentes podem significar o mesmo objeto de inúmeras maneiras. Sob um determinado olhar, alguns aspectos do objeto, antes não visíveis ou não apreciados, podem ganhar visibilidade. "Tudo depende, pois, da posição que adota aquele que olha. O lugar de onde se olha condiciona não somente o que se vê, mas também como se vê o que se vê" (Viñao Frago, 2008, p. 15). Uma perspectiva histórica da circulação dos abecedários em diferentes âmbitos do social, e não exclusivamente no sistema escolar, integra esses diferentes olhares.

\footnotetext{
${ }^{1} \mathrm{O}$ estudo integra as investigações em curso no âmbito do grupo de pesquisa "Histórias e memórias da educação brasileira e da cultura escolar", sob coordenação da profa. Dra. Maria Stephanou, com apoio do CNPq e da Fapergs.

2 O corpus documental sobre o qual se deteve o ensaio foi delimitado pelas cartilhas que integram o acervo Memória da cartilha, que reúne cartilhas e outros materiais referentes à alfabetização, como livros, relatórios, fotos, cd-roms, organizado pela profa. Iole M. F. Trindade, que se encontram disponíveis na Biblioteca da Faculdade de Educação da Ufrgs.
} 


\section{Segredos e palavras: dicionários e abecedários}

2013: Biblioteca Central da Ufrgs. Um achado: 1876, Lallemant Frères Tipografia de Lisboa, publicam em 16 volumes o Diccionario Popular - Historico, Geographico, Mytologico, Biographico, Artistico, Bibliographico e Litterario, dirigido por Manoel Pinheiro Chagas. Eis que no primeiro volume Abecedario está entre os vocábulos da extensa coleção e assim é definido:

Livro em que se aprende a ler. Colleção das letras que constituem os primeiros elementos de qualquer idioma. Nos antigos documentos dos séculos IX, X e XI em Portugal figuram letras dos abecedários ghoticos, romanos, ou toletanos. Mas no século XII começam-se a encontrar as letras dos abecedários francezes, que desde 1078 passaram dos livros ecclesiasticos para quase todas as escripturas d'aquelle tempo. Só no tempo de João de Barros se começaram a usar de novo em Portugal as letras romanas, em vez das letras gothicas. (Chagas, 1876, p. 81)

Na definição de Chagas, abecedário é livro de aprendizado da leitura. É também coleção de letras e modelos de diferentes letras ou traçados, inicialmente existentes nos livros eclesiásticos, modelos para os copistas, fórmulas para os livros manuscritos das escrituras religiosas. Abecedário, então, refere-se a alfabeto, abc; abecedário e alfabeto são palavras associadas, mas não coincidentes. Abecedário constitui um arranjo de letras, uma coleção e essa é uma distinção fundamental. Podem variar as letras de um alfabeto em diferentes idiomas, contudo, a coleção das mesmas constitui um abecedário. O Diccionario Popular remonta a definição aos antigos documentos dos séculos 9 a 10.

Segundo o Dicionário Houaiss da Língua Portuguesa (2001, p. 13), abecedário pode significar a série completa de letras capitulares, ou uma sequência alfabética das assinaturas de cadernos impressos; ou mesmo o que está disposto alfabeticamente e, portanto, que é alfabético. Assim, alfabeto e abecedário guardam entre si intensas relações. Contudo, e curiosamente, o mesmo dicionário apresenta 0 vocábulo abecedariano, expressão cuja história remonta ao século 16 e que, com a mesma palavra, diz-se de ou cada um dos membros da seita dos Abecedários, dissidentes do protestantismo que eram contra o aprendizado da leitura, pois acreditavam na ignorância absoluta como meio de salvação espiritual. Trata-se, portanto, de uma acepção relativa àquele que é ignorante (Houaiss, 2001, p. 13), no sentido de que desconhece o alfabeto e, por consequência, não realiza a prática da leitura. E assim dizia-se da seita dos Abecedários.

Também na obra dirigida por Chagas (1876) abecedários (no plural) está definida como palavra que significa "sectários anabaptistas, que affirmavam que para a salvação era indispensável a ignorancia até do alphabeto" (Chagas, 1876, p. 81). Assim, abecedário é palavra que se atribui tanto ao conhecimento quanto à ignorância do alfabeto.

Esses sentidos contrastados no tempo conduzem a reafirmar a importância da historicidade das designações, dos artefatos, dos significados e experiências que thes atribuem acepções diversas. Não há um sentido estável nas palavras, tampouco naquilo que designam. $\mathrm{O}$ mesmo sucede com abecedário, artefato cultural que é o objeto de investigação e reflexão neste ensaio. 
Os abecedários tem uma longa história, remontam mesmo à invenção dos sistemas de escrita e das convenções elaboradas para sustentá-las. Alguns autores, dentre os quais destacamos Duvallon (2010), mencionam a associação dos abecedários com aquilo que podemos entrever no uso das letras capitulares, que na Idade Média eram copiadas e traçadas, com paciência, arte e aplicação, pelos escribas ocupados com os textos religiosos manuscritos. Essas letras capitulares encontravam-se em meio a adornos, ou iluminuras, caracterizadas pelo tamanho e pelos desenhos ricamente ornados, coloridos, que as envolviam e emolduravam os textos, as páginas, as bordas das folhas, ou a primeira palavra e linha de uma frase.

De certa forma, as capitulares, sobretudo seus atributos estéticos e artísticos, foram alvo de atenções e, não raro, de coleções. Uma espécie de reunião dessas belas letras esboçava a emergência do abecedário como conjunto de letras do alfabeto. Havia, ainda, nesse mesmo período, a inscrição do abc completo como motivo decorativo em tapeçarias, arte difundida com destaque durante a Idade Média, e que recobria paredes, assim como o abc das genealogias bordadas e afixadas para memória das linhagens familiares. Importa demarcar, a partir destes exemplos históricos, os usos sociais e culturais, antes mesmo da adoção escolar dos abecedários como artefatos ligados aos métodos de ensino da leitura e da escrita.

Como parte do acervo da coleção da Real Biblioteca portuguesa trazida pela Família Real quando se mudou para o Brasil no início do século 19, e que, posteriormente, deu origem ao acervo da instituição cultural mais antiga de nosso país, a Biblioteca Nacional, consta entre os livros ilustrados um exemplar de iconografia sobre alfabetos e escrita, inclusa na obra de Pierre Aa Vander ${ }^{3}$, La galerie agreable du monde, volumes 49 e 50, publicada nos primeiros anos do século 18. Essas imagens possuem diferentes alfabetos caligrafados em desenhos adornados: alfabetos sírio, fenício, egípcio, armênio, chinês; abecedário cujas letras correspondem a desenhos de animais ou objetos, além das ilustrações de diversos apetrechos para a escrita (Schwarcz; Azevedo, 2003, p. 147).

Convém sublinhar que abecedários constam em diversas obras e manuais dedicados à caligrafia. A Real Biblioteca também legou à Biblioteca Nacional exemplares com essas características. Por exemplo, na obra Estímulos del divino amor, si agudos, suaves y dulces em doce solilóquios eucharisticos (1728-1729 apud Schwarcz; Azevedo, 2003, p. 219), manuscrito setecentista, o autor oferece numerosos desenhos, tarjas, vinhetas e capitulares que abrangem todas as letras sob diferentes traçados, acompanhados de prosa e versos que definem as origens e significados de cada letra, além de desenhos de difícil e paciente execução. Sobre a letra A:

La A es letra vocal y en orden de Alphabeto es la primera, asi en Hebreo como en Griego, Latino y Castellano \& En Hebreo se llama: Aleph, que significa Dux, Capitan, o Guia. En Griego: Alpha, que es lo mismo que

\footnotetext{
${ }^{3}$ Geógrafo e editor-livreiro holandês, estabelecido em Leyde, nascido em 1659 e falecido 1733. Iniciou suas publicações no início do século 18, em especial um grande número de mapas e registros de viagens. Suas edições de obras sobre botânica, medicina e antiguidades por Vaillant, Malphigi e Gronovius, obtiveram muito sucesso. A coleção de Pieter Van Der encontra-se conservada no centro de arquivos de Montreal, Biblioteca e Arquivos nacionais de Québec. É rara e possui grande valor histórico, havendo poucos exemplares ainda conservados, um deles em nossa Biblioteca Nacional. Galerie agréable du monde, constitui uma coleção de gravuras com explicações históricas em 66 volumes in-folio. Ver: http://fr.wikipedia.org/wiki/Pieter_van_der_Aa. 
Principio. En Arabe: Aliph o Alipha. En Caldeo: Elpha. En Egypcio: Athomus. En Indio: Eliph. En Sirio: Alyn. En Sarrazeno: Alemoxi. En Latin y en Castellano asi como fuera: A, que se forma com el aliento. (Schwarcz; Azevedo, 2003, p. 219)

Podemos afirmar que os livros de caligrafia e a estética caligráfica dos traçados mostram-se muito presentes nos séculos 17 e 18, quando ainda a letra manuscrita é imprescindível na criação e reprodução, para conservação ou circulação dos textos. Ainda como parte da Real Biblioteca, outras obras desse período propõem a domesticação, ou a maestria na escrita: Jose de Casanova, em Primera parte del'arte de escrivir todas las formas de letras (1650) nos oferece páginas gravadas, ricamente ilustradas com diferentes letras, seguindo as regras da ordem alfabética, ou dos tipos de traçados: na página 20 podemos ler Modo de formar las letras del bastardo con sus princípios, medíos y fines. Ou, na página 82, Principio para lós privilégios de letra del grifo que se escriven en el Consejo Supremo del Aragón y en el de Italia. En Madrid por el Maestro Casanova. (Schwarcz; Azevedo, 2003, p. 306).

Uma bela letra dá ares de civilização e bons costumes. Manuel de Andrade Figueiredo, mestre de Arte na cidade de Lisboa, oferece à augusta majestade Dom João V, rei de Portugal, a obra Nova escola para aprender a ler, escrever e contar (s.d. apud Schwarcz; Azevedo, 2003, p. 304). O estudo de letras, rigorosamente apresentadas na ordem alfabética por um abecedário com todos os detalhes de execução de cópias, consta na primeira parte, ilustração n. 3. Adiante, Andrade propõe outros exercícios de caligrafia e registra em seu manuscrito: "O exercício e Louvor das Letras que o Mundo aclama tem na nobreza o melhor berço, a que ilustra a fama, por mais sagrado esplendor" (Schwarcz; Azevedo, 2003, p. 305).

Vemos, assim, uma diversa circulação do abecedário ou de gêneros textuais que muito se assemelham aos propósitos de colecionar letras, ordená-las segundo princípios próprios, estabelecer modelos para aprendizado e cópia, ensinar a traçar com esmero, elegância, distinção social.

Os abecedários, ainda, integram obras que se voltam a recolher registros de viagens e antiguidades, muitas vezes associados às curiosidades de culturas, estilos e produções artísticas. A história dos abecedários como parte da cultura escolar moderna representa, então, apenas um breve momento de sua história de circulação e difusão nas sociedades de escrita.

Adotamos uma definição particular da palavra abecedário "a partir de uma acepção formulada com fundamento nas reflexões tecidas por Cagliari (2009) e Faraco (2012) acerca história da escrita" (Souza, 2015). Souza (2015) acrescenta que

abecedário como desdobramento da noção de alfabeto. Alfabeto como conjunto de caracteres que compõe um sistema de escrita, que adota como referência a relação entre grafema/fonema. $E$ abecedário como impresso cujo objetivo é proceder à didatização de cada uma e todas as letras do alfabeto com vistas ao ensino e aprendizado da leitura e da escrita. [...] abecedário e alfabeto não são sinônimos, embora visceralmente relacionados. Portanto, não coincidem, mas guardam entre si uma relação de implicação. (Souza, 2015, p. 13) 


\section{Das invenções: escrita, alfabeto, abecedários}

Os abecedários parecem ter vida longa na história da cultura escrita ocidental. Para Souza (2015) não existem, tampouco existiram, em qualquer sociedade, mas naquelas em que as letras e suas combinações, ou seja, o código escrito, passou a assumir uma centralidade, o que comumente designamos de sociedades grafocêntricas.

Cagliari (2003) entende que a escrita fonética - representada pelos sons - pode ser silábica ou alfabética. De acordo com Cagliari (2003), quem inventou a escrita concebeu, ao mesmo tempo, as regras que permitem ao leitor decifrá-la. Contudo, na perspectiva de que a escrita fonética é formada por elementos gráficos que representam sons, os silabários e abecedários parecem se mostrar como oportunos materiais ao ensino da leitura e da escrita, justamente por estabelecerem de modo específico tal relação, ou seja, a potencialidade da língua torna-se um convite à produção desses tipos de materiais.

Alain Choppin (2008) alude os abecedários e silabários que deram origem, posteriormente, às cartilhas. Primeiramente na Europa, durante a Idade Média, foi difundido o hornbook, em italiano tavola, em espanhol tableta, uma folha de papel sobre a qual estava reproduzido o alfabeto, a oração do Pai Nosso ou, ainda, os numerais de um a dez. No inglês, o nome deriva do tipo de suporte que sustenta o material didático, montado sobre um pedaço de madeira ou couro, ladeado por uma moldura de madeira ou metal, com a superfície protegida por uma fina película de corno ou chifre e, frequentemente, munida de uma alça.

A imagem abaixo mostra a materialidade dos hornbooks mais próxima da descrição feita por Choppin. Contudo, empreendendo uma busca no Google imagens é possível observar o uso de materiais diferentes para a confecção do hornbook, a variedade de tipos de letras utilizada na inscrição do abecedário e a escolha, pela presença ou ausência, de pequenos textos de conteúdo religioso ou dos numerais de 1 até 10.

Figura 1 -

Exemplar de Hornbook.

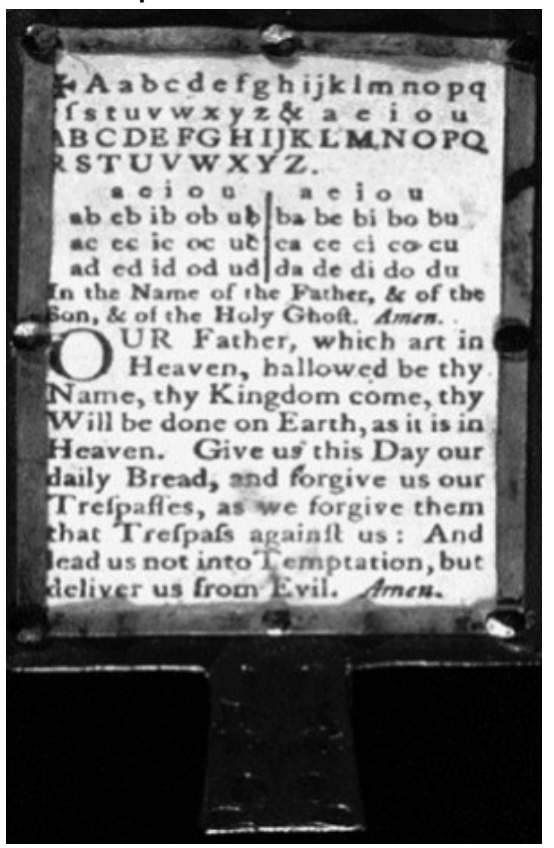

Fonte: http://histoire-education.revues.org/565. 
Choppin (2008) explica que derivado do hornbook, o battledore foi largamente difundido na Grã-Bretanha e nos Estados Unidos até metade do século 19. Com o aspecto de uma raquete, o battledore é uma folha de cartão dobrada em duas ou três partes, sob as quais de um lado está grafado o texto e, de outro, as ilustrações. Para o autor, apesar de sua aparência e nome (raqueta significa barulho, em inglês), os battledores nunca foram utilizados como jogos.

Figura 2 -

Exemplares de Battledore.
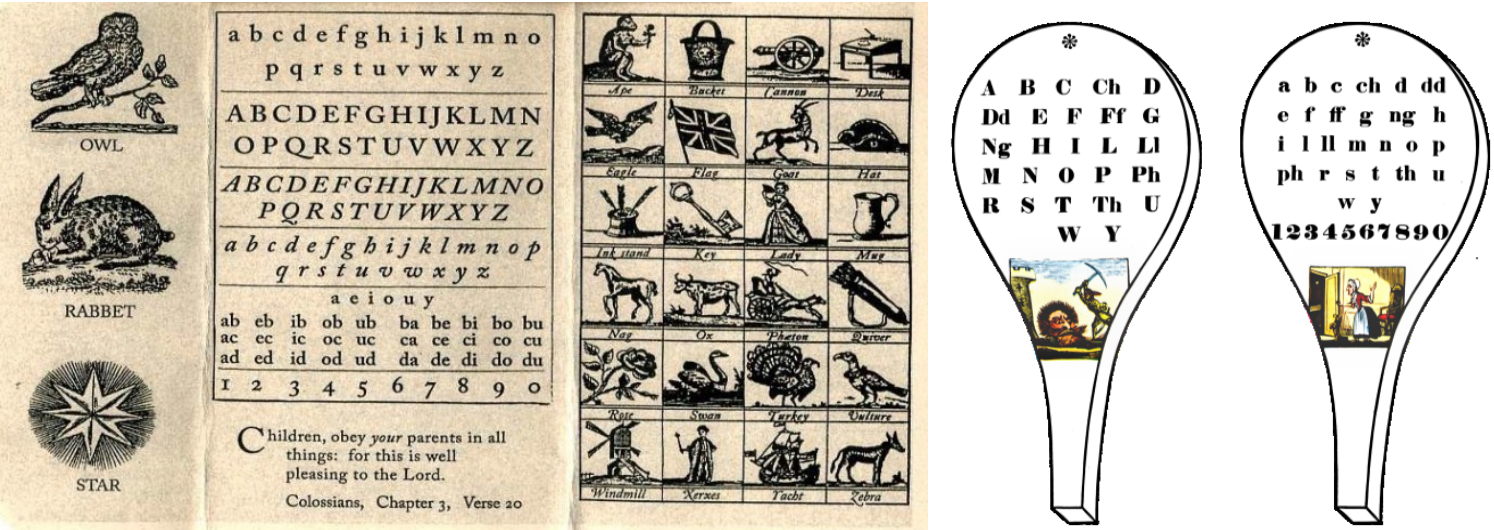

Fonte: http://commons.wikimedia.org/wiki/File:Battledore.png.

Conforme Choppin (2008), na Suíça o abecedário era designado pelo termo palette e podia ser encontrado desde o século 15. A palette tem a forma de pequena raquete triangular com uma parte lisa, onde se pode colar ou grafar um alfabeto manuscrito, e uma extremidade que se podia segurar com as mãos. A denominação palette permaneceu até o século 19, sendo utilizada para diferentes matérias.

Jean Hébrard ${ }^{4}$ (2002) examina uma classe de livros da Bibliothèque Bleue, produzidos pelos impressores de Troyes, na França do século 17, que tinha funções didáticas destinadas aos escolares ou "àqueles que querem aprender sem mestre" ( $p$. 11). $O$ autor refere que embora os abecedários sejam classificados como livros escolares, não é possível restringi-los somente a este uso, aspecto que frisamos anteriormente. Aponta que estas obras da coleção, voltadas à transmissão dos saberes elementares não estavam diretamente ligadas a um processo imediato de escolarização. Além disso, o objetivo de escolarização foi diferente para cada época e, portanto, os materiais usados no ensino das primeiras letras (doméstico, escolar) também podem ter sido diferenciados. Entre os livros da coleção Bibliothèque Bleu, o autor destaca o abecedário, e afirma que

é aquele que, certamente, representa a maior promessa de venda. Sob o nome de Instruções Cristãs - é assim que são chamados na França do leste - ele é, por excelência, o livro escolar do iniciante e, frequentemente,

\footnotetext{
${ }^{4} \mathrm{O}$ autor procede a uma espécie de arqueologia da leitura e da escrita, em especial referindo-se à realidade francesa e aos possíveis usos do abecedário nessa longa trajetória. Algumas das práticas descritas pelo autor podem ser contrastadas em sua regularidade ou permanência com a presença/ausência desses artefatos na história do Brasil.
} 
o único livro que ele possui. É verdade que ele oferece em um mesmo conjunto os instrumentos da primeira alfabetização e os textos essenciais da liturgia católica. (Hébrard, 2002, p. 12)

Para Hébrard (2002) estas obras e a transmissão dos saberes elementares não estão diretamente ligados a um processo imediato de escolarização. Além disso, o objetivo de escolarização foi diferente para cada época e, portanto, os materiais usados no ensino das primeiras letras (doméstico, escolar) também podem ter sido diferenciados.

Outros autores comentam a trajetória histórica dos abecedários no contexto francês. Carrete e Péron (2007) registram que o abc, ou abecedário, era utilizado na França como método de aprendizagem desde o século 15; posteriormente, o abecedário e seus variantes restaram muito tempo em uso nas escolas. Em 1705, por exemplo, em uma escola paroquial, descreveu-se: "à maneira de primeiro alfabeto" um pequeno livro de quatro ou seis folhas em uso nas pequenas escolas de Paris. Os autores assim o descrevem: sobre a primeira folha, constavam traçadas as 23 letras comuns do alfabeto; em seguida, o alfabeto tomado em decrescente a partir da última letra. A segunda folha continha as 23 letras capitais, depois o mesmo alfabeto em decrescente. Vinham em seguida, na terceira folha, as 24 letras itálicas, depois, na quarta página as ligações de diversas letras que em conjunto compunham um caractere e certo número de abreviaturas que constavam já nos livros que foram impressos no começo do século 18 e que era preciso que as crianças as aprendessem para leitura dos velhos textos. Por fim, na quinta e sexta folhas, dois alfabetos de antigos caracteres góticos (Carrete; Péron, 2007, p. 26).

Registram, ainda, que no século 18, houve autores que desejavam renovar os antigos métodos de educação e propunham que o estudo se tornasse mais fácil e atraente, como os sistemas de ensino do gramático Py-Poulain Delaunay, ou depois de Dumas, que misturavam alfabeto e silabário à pronunciação verbal, utilizando um acessório: a bancada ou mesa tipográfica [com as letras do alfabeto em separado e colocadas em degraus de um suporte de apoio confeccionado em madeira e sobre a mesa]. Esta ideia de uma bancada tipográfica de Dumas será retomada mais tarde na França pelo método Thollois de ensino do alfabeto (Carrete; Péron, 2007, p. 27). No século 19 não houve um conjunto expressivo de inovações, segundo Carrete e Péron (2007), embora os métodos tenham embelezado os abecedários que passaram a ser ilustrados - ou alfabeto em imagens - complementando os abecedários tradicionais e os silabários. Os autores indicam que assim procedeu Jacotot, propondo um ensinamento analítico que partia da frase para chegar à letra, ou um método sintético privilegiando a letra, ou então a leitura sem soletração de Lamotte, Perrier, Meissas e Michekot (Carrete; Péron, 2007).

Baseada nos estudos de Anne-Marie Chartier (2004), Isabel Frade (2010) menciona que os inúmeros abecedários ilustrados que circularam na França por vezes voltaram-se a um público mais restrito. Isso pode ter acontecido por se tratar de um material mais luxuoso, daí que seu uso se reduziu aos espaços privados e domésticos. Além disso, a autora afirma que os livros de imagens tinham como objetivo estimular o interesse da criança pelo desejo de aprender a ler. Mesmo que apresentassem uma sequência de letras, eles podiam ser folheados aleatoriamente, uma vez que seu formato, em códice, 
permitia tal manuseio. Sobre os gestos de leitura, discute que a criança, durante a interação com o objeto, poderia focalizar uma letra ou ilustração e com o auxílio de um adulto, ler o que ali estava inscrito. Podia, ainda, gravar a ordem das letras, seus nomes, identificá-las quando fora da ordem, memorizar um conjunto de sílabas e de palavras a serem soletradas. Tratando desses aspectos, Frade (2010) esclarece que esse tipo de abecedário era direcionado às elites, e a posse mais restrita desencadeava diferentes apropriações do material.

Quanto a este aspecto, Duvallon (2010) registra que na França os abecedários foram abundantemente difundidos desde o início do século 19, chamados também de alfabetos ou $A B C$, a serem utilizados em casa para a sensibilização das pequenas crianças à aprendizagem do alfabeto, passagem obrigatória para aceder à leitura e à escrita. Nessa referencia é instigante o fato deste autor não mencionar que os abecedários começam a ser usados como dispositivo escolar.

Até aqui procuramos demonstrar que abecedários, ofertados à leitura e cópia em diferentes materialidades, possibilitou que viessem a transitar entre o uso doméstico e o uso escolar, havendo uma semelhança fundamental: em ambos os espaços este material esteve associado ao ensino inicial da leitura e da escrita. Consoante ao segundo uso, o uso escolar, Choppin (2008) entende que o conteúdo do livro escolar também pode ser fator relevante para a classificação dos abecedários. Em uma distinção mais tradicional, a literatura escolar é classificada em dois grandes conjuntos: de um lado os livros que apresentam os conhecimentos (livros de matérias) e, de outro lado, os que visam a aquisição dos mecanismos de leitura (livros de leitura). Choppin (2008) mostrou-se especialmente interessado pela segunda categoria de livros escolares da definição mais tradicional, que compreende os métodos de leitura, como os alfabetos e abecedários, que distinguiu sob três tipos:

a) Alfabetos e abecedários: inglês - alphabet book; italiano - abbecedario.

b) Silabários: inglês - spellers; espanhol - silabário.

c) Livros de leitura: inglês - primers readers, assim designados porque constituem os primeiros livros; espanhol - libro de lectura; português - livro de leitura.

A partir de autores franceses, como Hébrard (2002) e Chartier (2004), acrescentaríamos ao primeiro itemo seguinte: francês - abécédaire.

A França apresenta longa tradição de produção deste tipo de material. Segundo Hébrard (2002), o abecedário é, efetivamente, um dos produtos de base de todos os pequenos impressores da realidade francesa: "Uma prensa e algumas fundições de caracteres são suficientes para imprimir um abecedário" (p. 12).

Retomando a classificação dos manuais escolares, Escolano (2000) afirma que na Espanha havia diferentes tipos de livros de textos no ensino primário: os que se voltavam aos "exercícios de leitura" (p. 27) e as obras destinadas ao estudo das demais matérias. No âmbito do primeiro grupo, incluíam-se as obras destinadas à aprendizagem da leitura, a saber: abecedários, silabários, cartilhas. De acordo com o primeiro critério, de natureza pedagógica, os livros escolares podem ser inscritos em alguma das seguintes categorias propostas por Escolano (2000): livros de iniciação; séries cíclicas; modelos enciclopédicos, textos de caráter sincrético; livro-guia; livro de consulta; livro ativo. 
Os abecedários e silabários, conforme o autor, integram o primeiro grupo, os livros de iniciação. Choppin (2008) e Escolano (2000) compartilham do mesmo entendimento. Abecedários constituem artefatos que possuem uma função didática para o exercício inicial da leitura, não exclusivamente na escola.

\section{Os abecedários na tradição dos manuais escolares}

$\mathrm{Na}$ história da educação escolar, notadamente na história dos artefatos escolares, observamos que os abecedários foram postos em circulação em diferentes suportes: desenhados cuidadosamente pelo professor em ardósias, quadros de giz; apresentados em cartazes afixados nas paredes das salas de aula; reunidos em caixas, como peças móveis, ou depositados em mesas especiais, sobre as quais foram acopladas caixas de madeira e letras móveis sob inspiração dos instrumentos de tipografia (Carrete; Péron, 2007), e, com maior frequência, abecedários impressos em pequenos livretos ou em manuais escolares do ensino primário.

A partir dessa afirmação, interessa-nos sobremaneira as cartilhas escolares que portam abecedários, que consideramos, a partir de Escolano (2000) como livros ou manuais escolares. Constituem não apenas um elemento material de auxílio a alunos e professores, mas, como sugere o autor, a "representação concreta de todo um modo de conceber e praticar o ensino" (p. 15).

Propomos pensar uma hierarquia ${ }^{5}$ dos modelos didáticos voltados para o ensino e aprendizado da leitura e escrita. O alfabeto enquanto conjunto de letras usadas na grafia de uma língua precisa ser ensinado e aprendido por uma tradição secular que não é apenas um imperativo escolar, mas também cultural. $O$ abecedário, conjunto de letras do alfabeto, assume o papel didático de ensino e estabelece uma relação fonema/grafema. Pode ser considerado o primeiro modelo da relação hierárquica. Em seguida, o silabário complexifica um pouco mais as relações linguísticas, na medida em que estabelece combinações entre elas, fazendo agrupamentos entre consoantes e vogais, por exemplo: ba - be - bi - bo - bu. Segundo Choppin (2008), existem impressos que reúnem ambos, abecedários e silabários: são por excelência as cartilhas. As cartilhas são modelos de impressos didáticos que ocupam a terceira posição nessa hierarquia.

\section{Os ABC's e abecedários em cartilhas do acervo Memória da Cartilha/Ufrgs}

O total de cartilhas repertoriadas no Acervo Memória da Cartilha foi de 205 exemplares, dentre as quais se referem à alfabetização inicial 173 cartilhas. Deste total estabelecemos como critério de seleção examinar aquelas que possuem abecedários impressos. Além das cartilhas, o referido acervo contém três abc's com características que podemos aproximar aos abecedários ilustrados franceses.

\footnotetext{
${ }^{5}$ A intenção não é propor a hierarquização de modelos na conotação do que seria melhor ou pior para o ensino e aprendizado da leitura e da escrita. Tampouco na intenção de estabelecer uma ordem de utilização dos mesmos. 
O gráfico abaixo apresenta o número de cartilhas do acervo, distribuídas pelos anos identificados. Observa-se que há 46 exemplares que não constam data de publicação exata, o ano de 1919 está contemplado com um único exemplar, a década de 50 apresenta 67 cartilhas seguido da década de 60 com 51 cartilhas. $O$ ano de 1973 possui somente um exemplar.

Figura 3 -

Levantamento de cartilhas com abecedários.

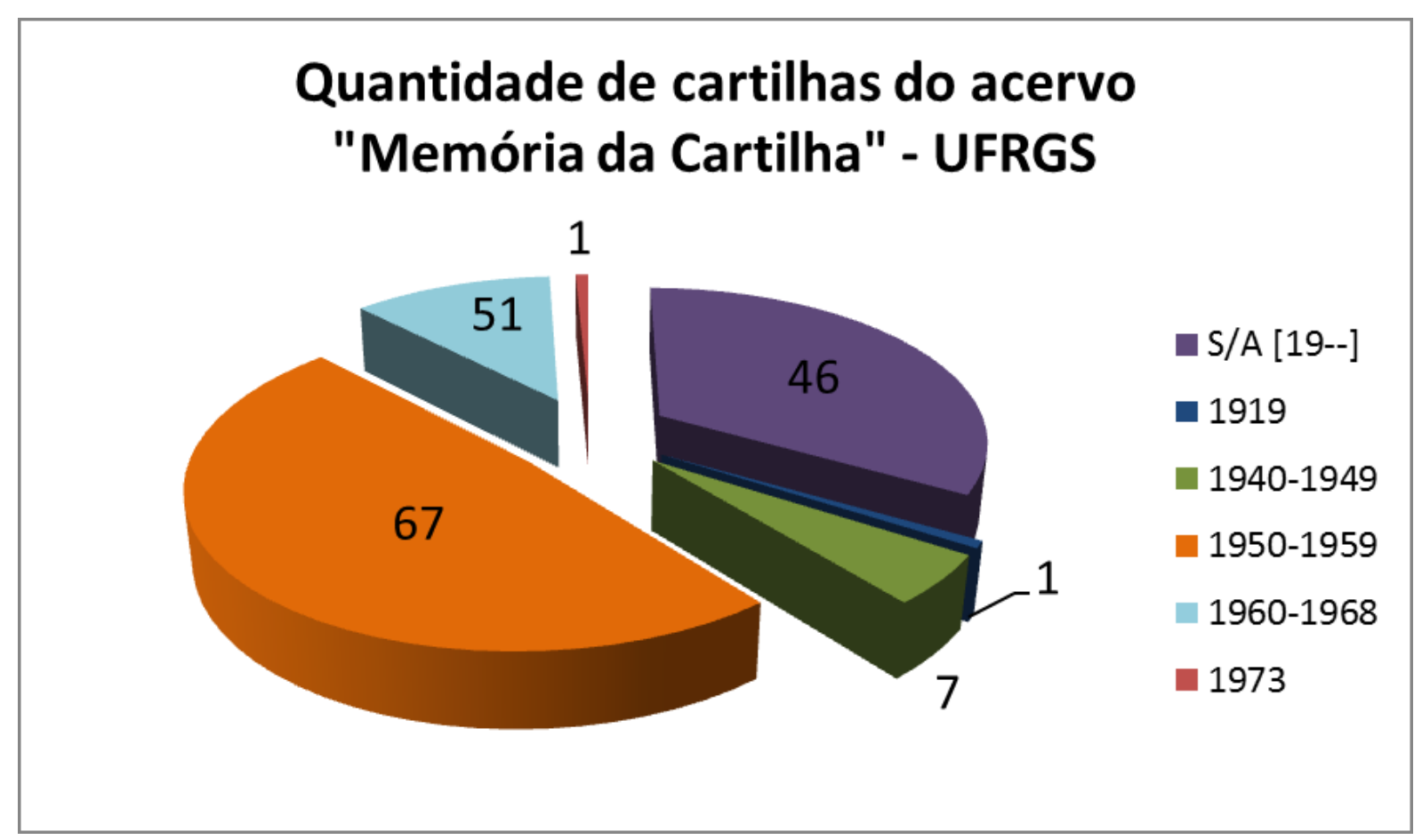

Do conjunto de 173 cartilhas, somente 87 delas possuem o abecedário em seu conteúdo, o que representa aproximadamente $50 \%$ dos impressos identificados. O gráfico abaixo demonstra a quantidade de cartilhas com abecedário nas datas de publicação indicadas nos suportes. Quantos às cartilhas sem indicação precisa de ano, dos 46 exemplares identificados, 29 possuem o abecedário (equivalente a 63\%). No ano de 1919 o único exemplar apresenta o abecedário. No período de 1940 a 1949, 42\% das cartilhas, ou seja, pouco menos da metade delas contém o abecedário. Na década de 50 , dentre as 67 cartilhas do Acervo, 37 delas possuem abecedário, ou seja, 55\%. Nos anos de 1960 a 1968, 16 cartilhas possuem o abecedário de um total de 51 , sendo, então, somente $31 \%$. No ano de 1973, a única cartilha existente no Acervo não possui abecedário. Uma constatação: em comparação com todos os demais períodos, a década de 60 , nesta amostragem, é a que menos adere ao uso do abecedário impresso no material dedicado ao ensino inicial da leitura e da escrita. 
Figura 4 -

Distribuição temporal das cartilhas com abecedários identificadas.

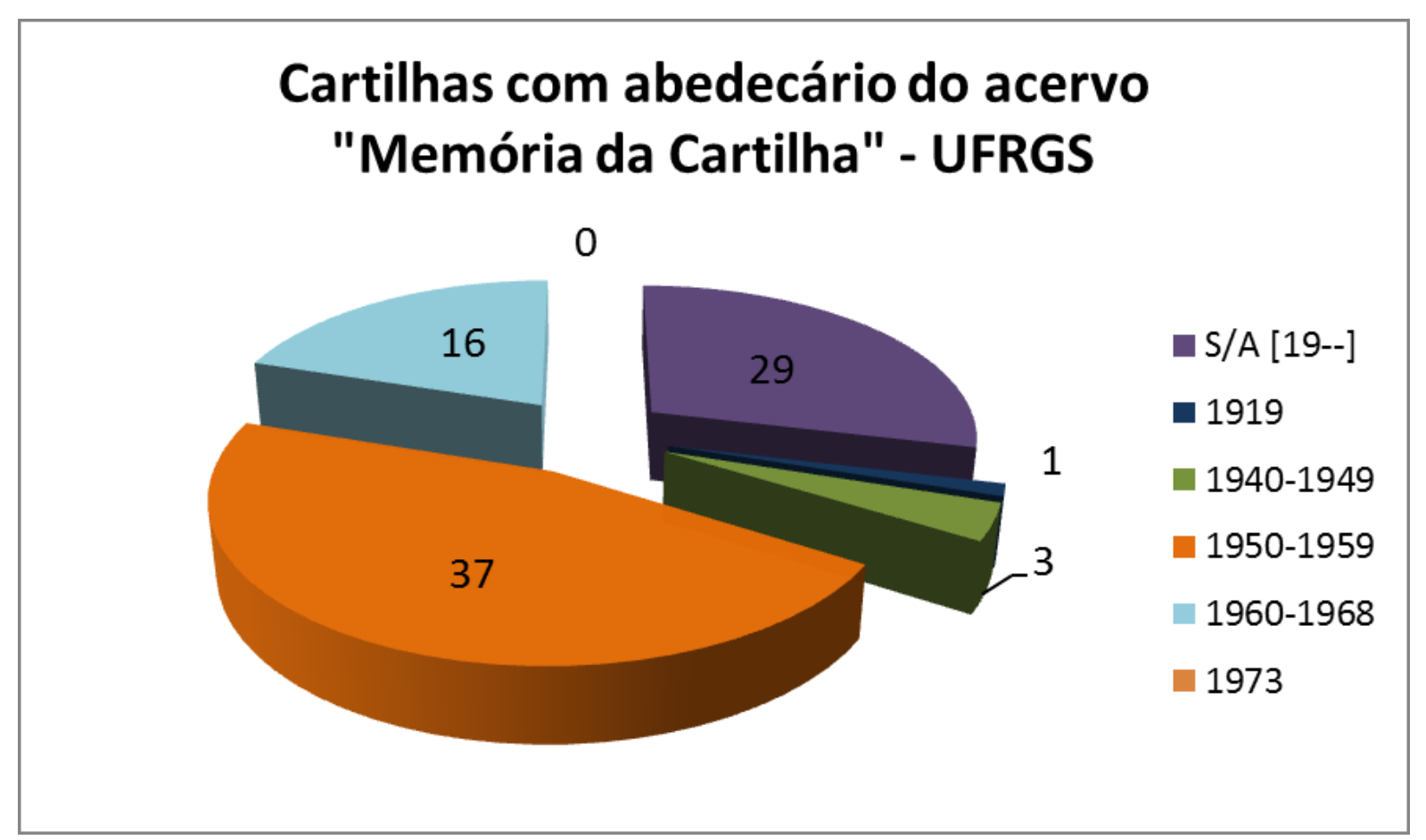

Selecionamos os seguintes períodos para uma apreciação em maior destaque: 1919, 1940 a 1949 e os ABC's disponíveis no acervo do ano 1965.

\section{A cartilha Queres ler?}

A cartilha nomeada Queres ler? ${ }^{6}$, foi adaptada do Uruguai para o Brasil por Olga Acauan Gayer e Branca Diva Pereira de Souza (1919). Na versão uruguaia foi elaborada por José Henríquez Figueira, sendo intitulada Quieres leer?

Segundo Trindade (2004), Protásio Alves, que exerceu mandatos de vice-presidente da Província do Rio Grande do Sul e de secretário do Interior e do Exterior, em seu relatório de 1914 sugeriu ao presidente do Estado que seria muito importante, a serviço de instrução pública, que os livros didáticos que não prestassem convenientemente ao ensino, fossem substituídos.

No relatório anual de 1914 à $3^{a}$ diretoria, conforme Trindade (2004), Paim Filho informa a ida de uma missão de professores a Montevidéu para a observação dos métodos de ensino que eram adotados pelas escolas uruguaias, uma vez que a República vizinha era considerada um tanto adiantada no tocante à educação. Neste mesmo relatório informa que algumas alunas mestras da Escola Complementar, que estavam concluindo o curso, também participariam da missão. Entre este grupo, estavam Olga Acauan Gayer e Branca Diva Pereira de Souza, que mais tarde seriam as futuras

\footnotetext{
${ }^{6}$ A escolha pela cartilha Queres ler? foi motivado pelo tema central do Encontro Sul-Rio-Grandense de Pesquisadores de História da Educação de 2013. 
autoras do primeiro livro Queres ler?, "obra que seria aprovada pela Comissão de Exame das Obras Pedagógicas em 1924 e indicada por essa Comissão para adoção na instrução pública em 1929" (Trindade, 2004, p. 322).

Figura 5 -

Capa da cartilha Queres ler?

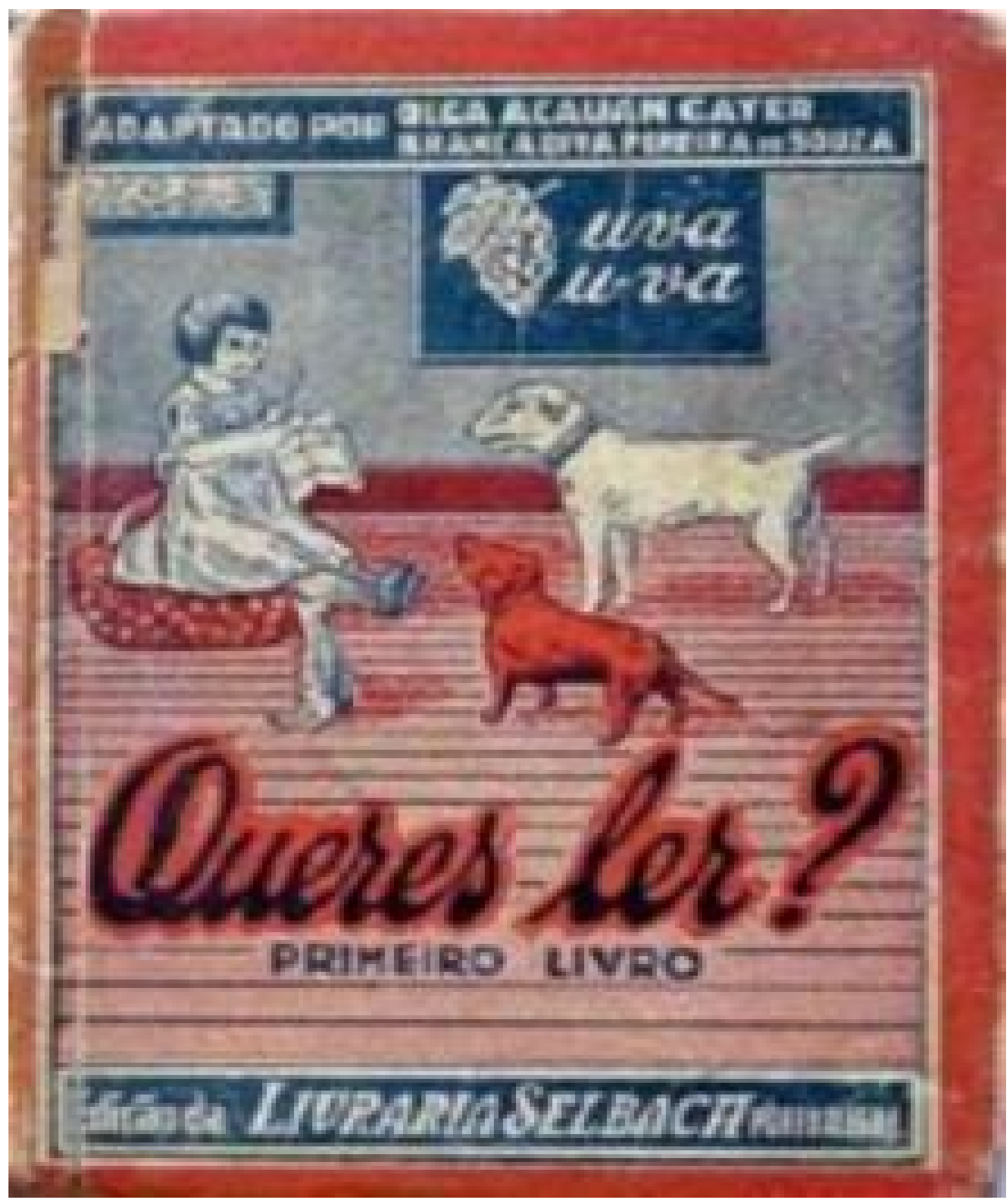

Para Trindade (2004) um dos motivos para esta obra ter obtido tal reconhecimento, estaria relacionado ao fato de fundamentar-se no método analítico, que, na época, era considerado uma inovação da pedagogia moderna. Segundo a autora, para que 
possamos entender o motivo pelo qual o governo gaúcho "acabou construindo essa passagem de uma cartilha portuguesa [Cartilha Maternal] para um primeiro livro uruguaio", é preciso tomar conhecimento da trajetória das adaptadoras da obra (p. 327). Contudo, em função das características deste ensaio, não há como descrever minuciosamente todos os aspectos envolvidos. O primeiro deles relaciona-se ao método de alfabetização adotado, analítico,; à estrutura dos exercícios em série graduada; a boa adaptação do idioma; a exploração dos exercícios de leitura simultâneos aos de escrita; a questão da escolha para o traçado da letra - poderia ser tanto vertical quanto um pouco inclinada -, ou seja, as autoras privilegiam e valorizam a boa escrita ou boa letra em oposição à escrita caligráfica. Acreditavam que a boa letra seria uma consequência natural do ensino da escrita e não uma escrita especial exercitada em cadernos de pauta caligráfica.

Nessa cartilha o abecedário está impresso nas páginas centrais do livro e apresentase em letra imprensa, assim nomeada - maiúscula e minúscula -, e sob um tipo de letra caligráfica inclinada - maiúscula.

Figura 6 -

Página da cartilha Queres ler?

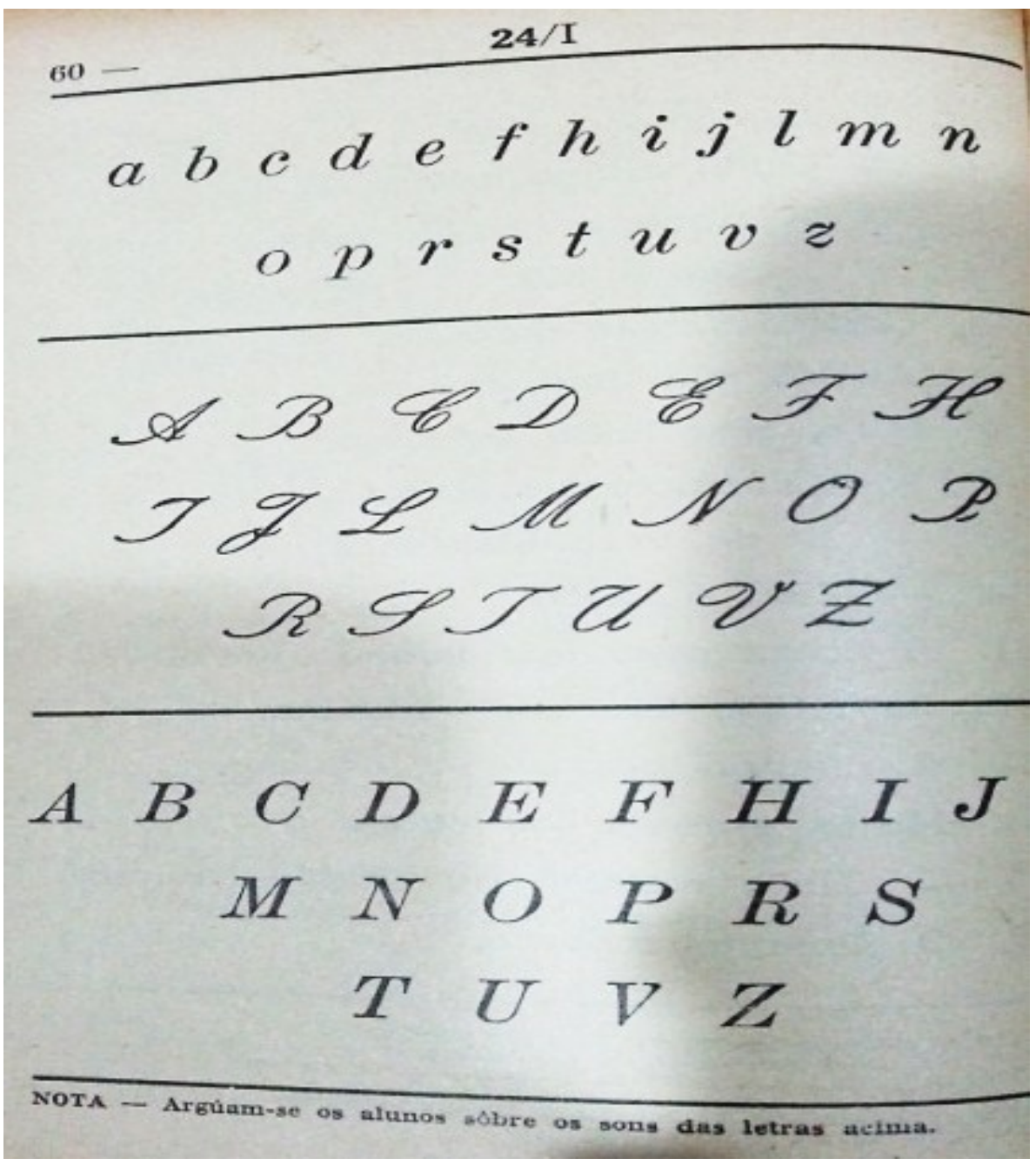


Uma nota de rodapé recomenda: "argúam-se os alunos, sôbre os sons das letras acima" (Gayer; Souza, 1919, p. 60). A indicação das autoras, neste momento, parece desejar que os alunos relacionem grafema/fonema. Em outras palavras, fica expressa a indicação de um uso para o abecedário: a leitura. Na página seguinte, aparecem algumas letras do alfabeto, elas enfatizam a aprendizagem dos dígrafos - noção de conhecimento linguístico -, depois a grafia aproximada de algumas letras no modelo script minúsculo, por exemplo b, d, p. Em nota de rodapé as autoras aconselham que as crianças observem as semelhanças e diferenças entre as letras. Sobressai, então, uma dimensão da escrita mais acentuada, embora conhecer o traçado das letras também possa relacionar-se à leitura. Para Stephanou e Bastos (2008),

no universo escolar, ensinar a escrever é tarefa imprescindível ao processo de alfabetização. O domínio da escrita implica um conjunto de saberes e habilidades complexas: não só identificar as letras do alfabeto, mas desenhá-las com clareza, destreza, domínio da mão e dos instrumentos necessários. Além disso, coordenar o uso da folha branca, aprendendo a distribuir bem os espaços. Para isso, o verbo imperativo nos primeiros estágios escolares de aquisição da escrita é praticar e realizar exercícios variados, didatizados pela escola. (p. 2)

Em uma das lições da cartilha Queres ler? as palavras e imagens em jogo são: ovo e uva. Em nota de rodapé as autoras aconselham que seja usada, inicialmente e de modo repetitivo, a letra manuscrita para depois proceder-se à apresentação da letra imprensa. Recomendam para as crianças atrasadas - desse modo chamadas -, que a professora faça o traçado das letras no ar e as crianças com os olhos fechados e abertos as reproduzam. De algum modo essas prescrições explicam alguns usos possíveis do abecedário quanto à dimensão da escrita: auxiliar na verificação do traçado para utilização adequada no momento do registro.

Especificamente o abecedário não está associado a uma imagem. No caso desta cartilha são as lições que apresentam duas ou três delas. $O$ abecedário parece indicar tanto a função relacional entre letra/som quanto servir como modelo de letra para o traçado manuscrito.

\section{O abecedário nas cartilhas de 1940 a 1949}

Nas cartilhas intituladas O bom colegial (1948), Sei ler: leituras intermediárias (1949) e Ler brincando: nova cartilha (Andrade, 1949) o abecedário encontra-se impresso no meio da cartilha, miolo central, se as tomamos como exemplares físicos. Nelas consta também uma espécie de texto de orientação didática que prescreve o modo como o alfabeto deveria ser ensinado ou abordado pelo professor. Em Ler brincando consta que

Para o conhecimento das 23 letras em ordem alfabética far-se-á com que os alunos vão guardando as palavras das tirinhas cortadas, numa pequena caixa com 23 divisões. Tais palavras são distribuídas pelas letras iniciais de $A$ a Z . Também no quadro-negro, poder-se-á organizar um quadro, como o das páginas 118 e 119, onde as palavras vão aparecendo, uma a uma, no correr das lições. (Andrade, 1949, p. 137) 
Figura 7 -

Capa da cartilha Ler brincando.

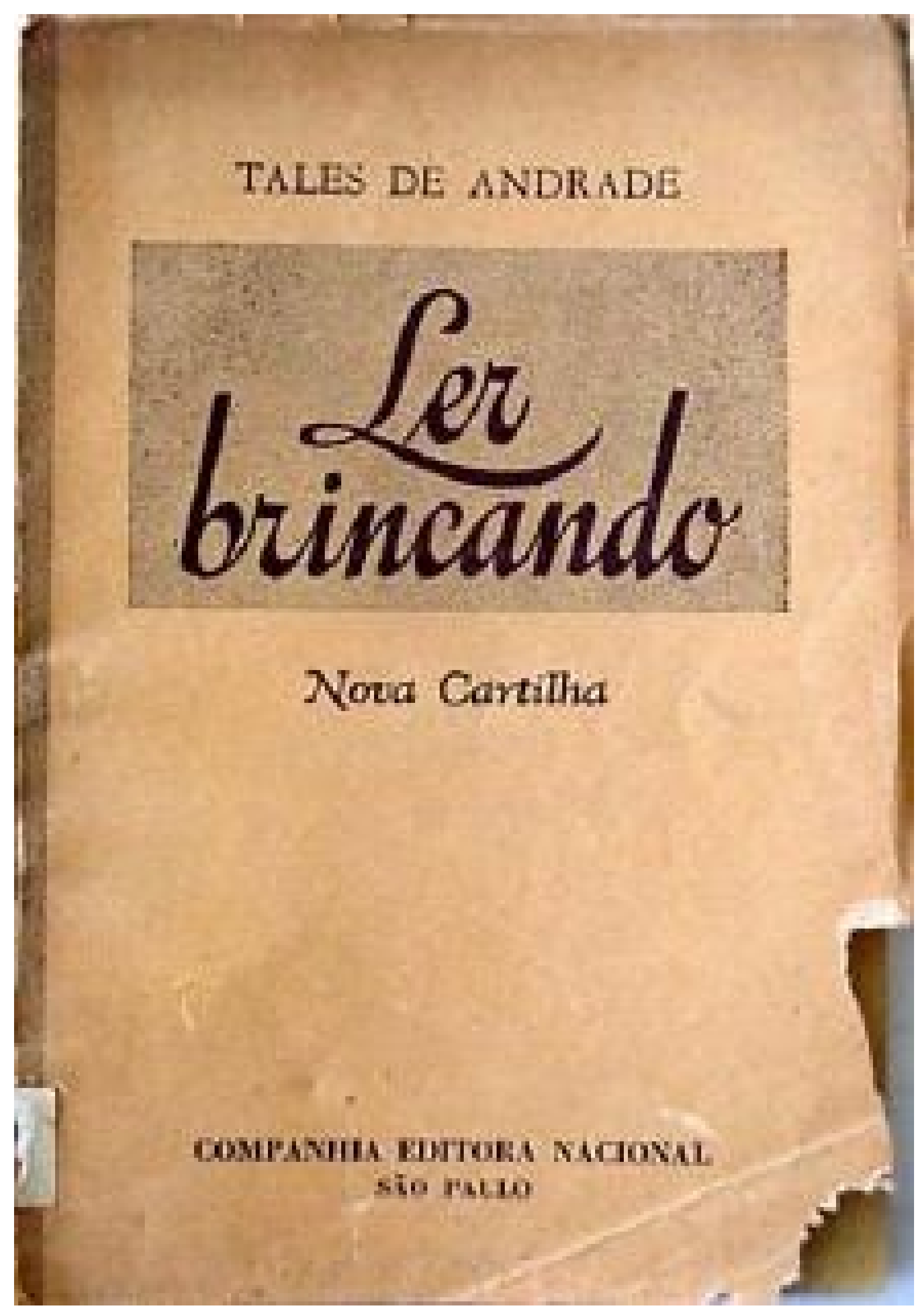


Figura 8 -

Página da cartilha Ler brincando.

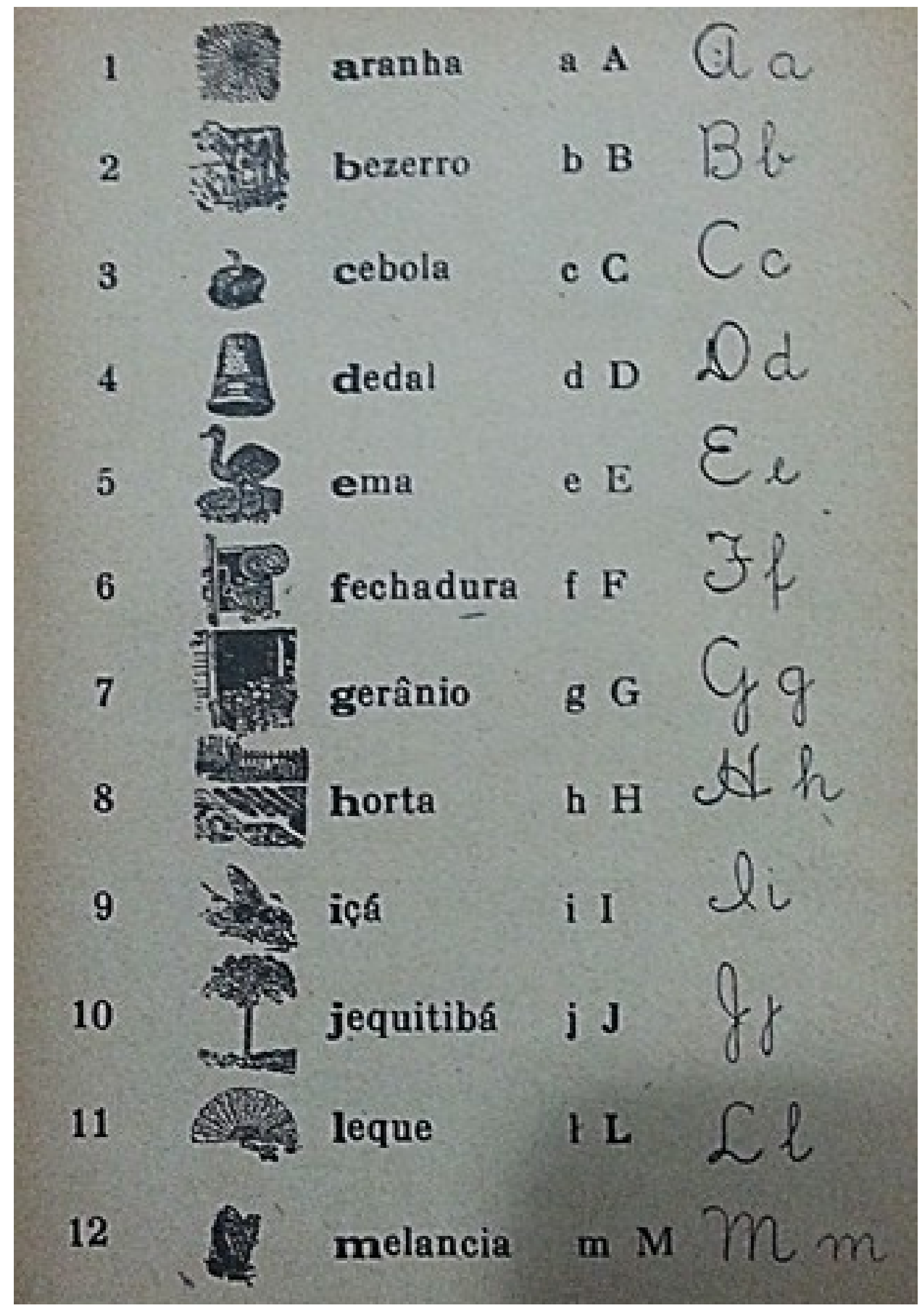


Parece haver a indicação de associar o abecedário a uma questão gramatical, a ordem alfabética. Além disso, aconselha-se a produção de tirinhas, ou seja, um material complementar que funcionaria como apêndice da cartilha. Recomenda-se, também, que acima do quadro-negro houvesse a exposição das letras do alfabeto agregadas às palavras enfatizadas nas lições. O abecedário parece estar associado, neste caso, muito mais ao ensino da leitura do que da escrita. A imagem reproduzida ao lado, da cartilha Ler brincando exibe a relação entre figura, palavra e letras, script e cursiva, na versão maiúscula e minúscula.

Em outra cartilha, denominada O bom colegial (Freitas, 1948), o abecedário consta com letras script e um tipo de letra caligráfica. Não associa palavras ou imagens às letras, como podemos observar na Figura 10.

Figura 9 -

Capa da cartilha O bom colegial.

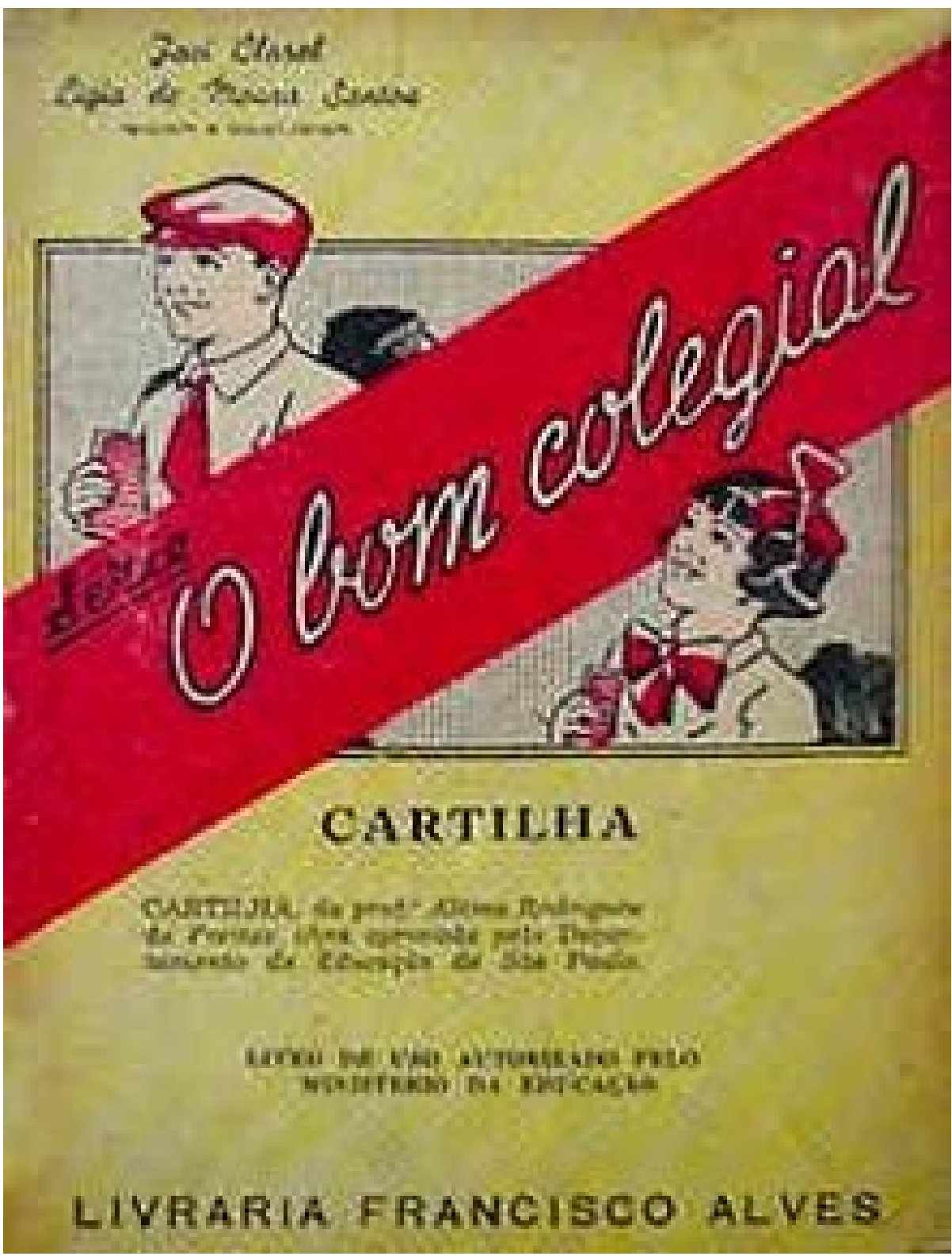


Figura 10 -

Página da cartilha $\mathrm{O}$ bom colegial.

$$
\begin{aligned}
& a b c d e f g h i \cdot g=l_{n} \\
& \text { nopqrstuv } x, z \\
& a b c d e f g h i j / m \\
& \text { n } \circ \text { p } q r \text { s } t \quad u \quad v \quad x \quad z \\
& \text { ABCDE } 3 \text { Gistl of } \mathrm{Lm} \\
& \text { nOPQR\&JUVxz } \\
& A B C D E F G H \mid J L M \\
& \text { NOPORSTUVXZ }
\end{aligned}
$$

O modo como o abecedário está impresso consiste na inscrição de letras minúsculas, caligráfica e script e letras maiúsculas, caligráfica e script. Trata-se, pois, de uma pequena diferença em relação à cartilha Ler brincando (Andrade, 1949) que comentamos anteriormente.

Relativamente à escolha da letra, a cartilha Sei ler: leituras intermediárias (Morais, 1949), opta por imprimir somente a letra script maiúscula. 
Figura 11 -

Capa e página da cartilha Sei ler.
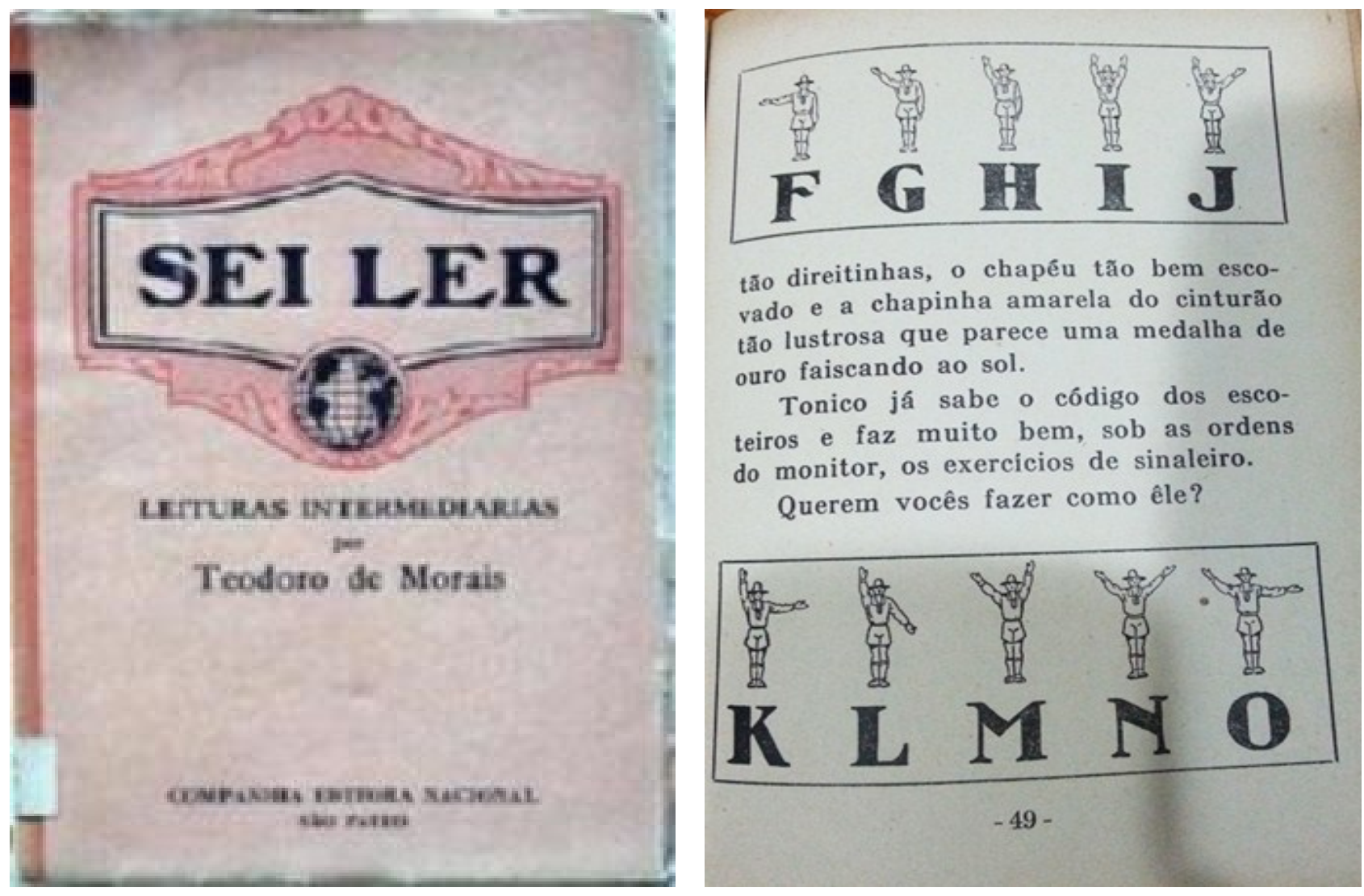

É possível perceber, através do exposto, que o abecedário mostra imagens de um escoteiro, o Tonico. Elas desenham, com os movimentos de seu corpo, o traçado das letras. Há um texto entre os grupos das letras cujo sentido principal é indicar que Tonico sabe o modo asseado que os escoteiros vestem o uniforme. Sabe também o código dos escoteiros e faz muito bem, sob as ordens do monitor, os exercícios de sinaleiro (p. 49). Com a pergunta "Querem vocês fazer como êle?" o texto convida as crianças a conhecerem com Tonico as letras do alfabeto. Em outras palavras, ele conhece o código dos escoteiros e as crianças são convidadas a conhecerem outro código, o alfabeto.

\section{Os ABC's}

$O A B C$ das aves, exemplar único no acervo, em sua $3^{a}$ edição, foi publicado em 1965. Sua forma é a do códice, indica o nome do ilustrador, sem paginação, sem constar qualquer texto instrutivo acerca de como utilizá-lo no ensino.

Está organizado de $A$ a $Z$, sem a inclusão das letras $K, X, Y, W$. A letra script maiúscula e a letra minúscula estão em destaque, pelo uso de cores diferentes para cada uma delas. Há, também, um tipo de letra caligráfica em versões maiúscula e minúscula. A imagem da ave ocupa quase a dimensão de uma página e seu nome é escrito em script maiúscula e caligráfica. Esta última possui a letra inicial maiúscula e as demais minúsculas. Toda a sequência das páginas segue este padrão, alterando as letras e imagens. 
Figura 12 -

Capa da cartilha $O A B C$ das aves.

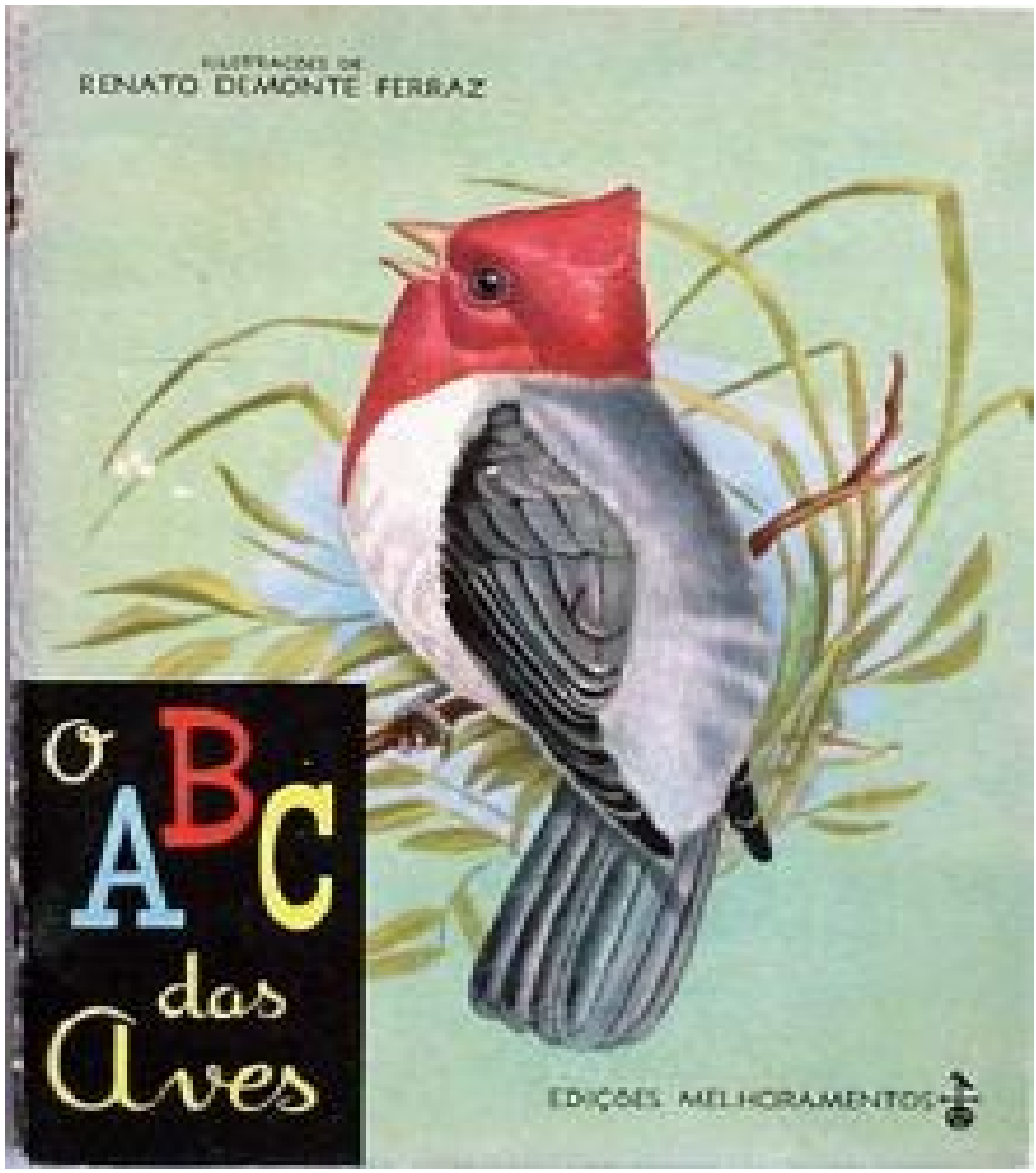


Figura 13 -

Página da cartilha $O A B C$ das aves.

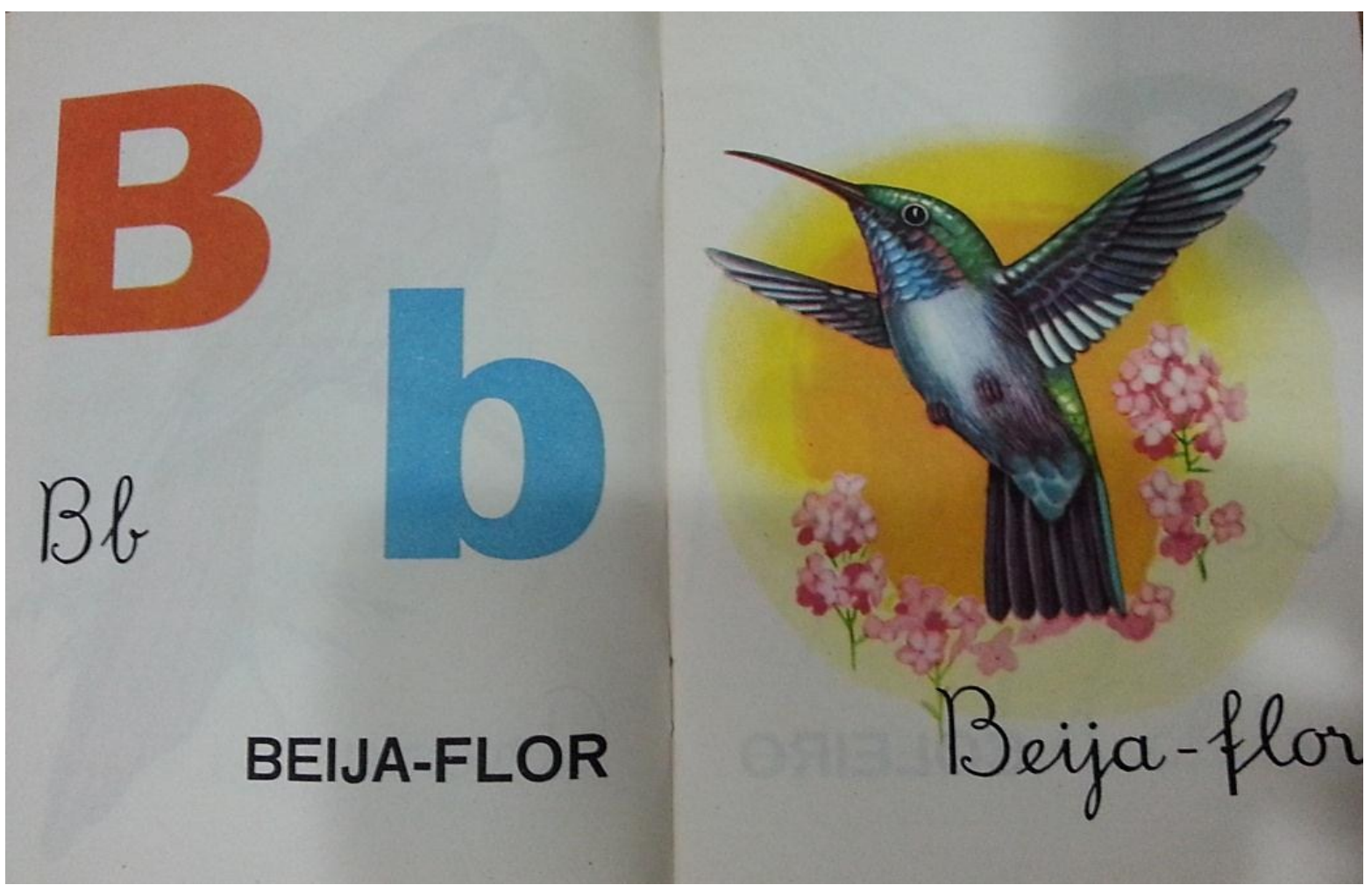

No acervo consta também o abecedário intitulado Meu $A B C$. Há dois exemplares de edições diferentes. Uma corresponde à $4^{a}$ edição e não há indicação de ano. $O$ outro exemplar é da $12^{\mathrm{a}}$ edição, referente ao ano de 1965. Essa informação nos leva a estimar que o exemplar cuja referência ao ano inexiste, possivelmente seja do final da década de 1950 ou início da década de 1960.

A $4^{a}$ edição do $M e u A B C$ apresenta-se em formato de códice, indica o nome da ilustradora, sem paginação, sem algum tipo de texto instrutivo acerca de como usá-la. 
Figura 14 -

Capa da cartilha Meu ABC.

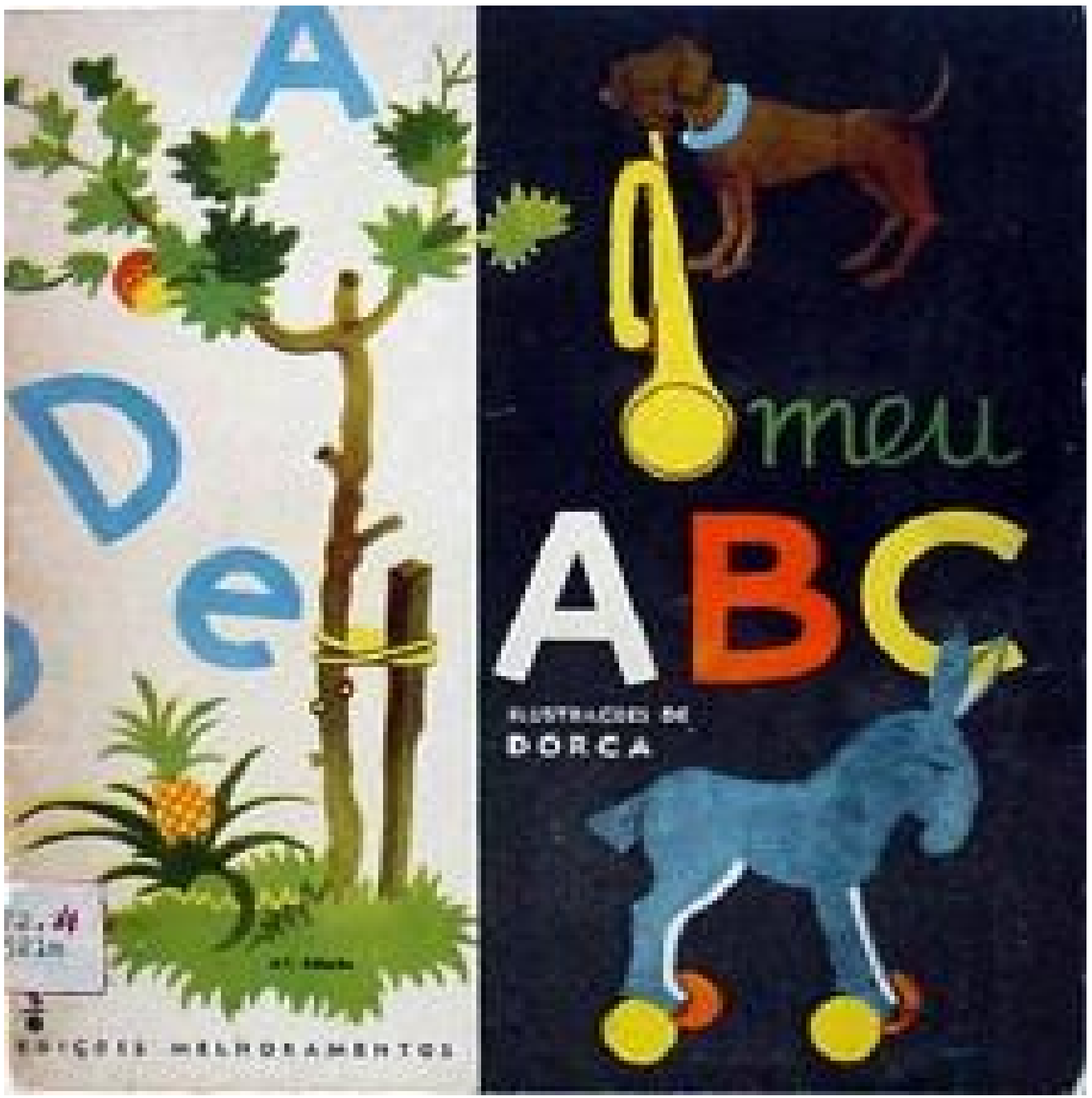


Figura 15 -

Página da cartilha $M e u A B C$.

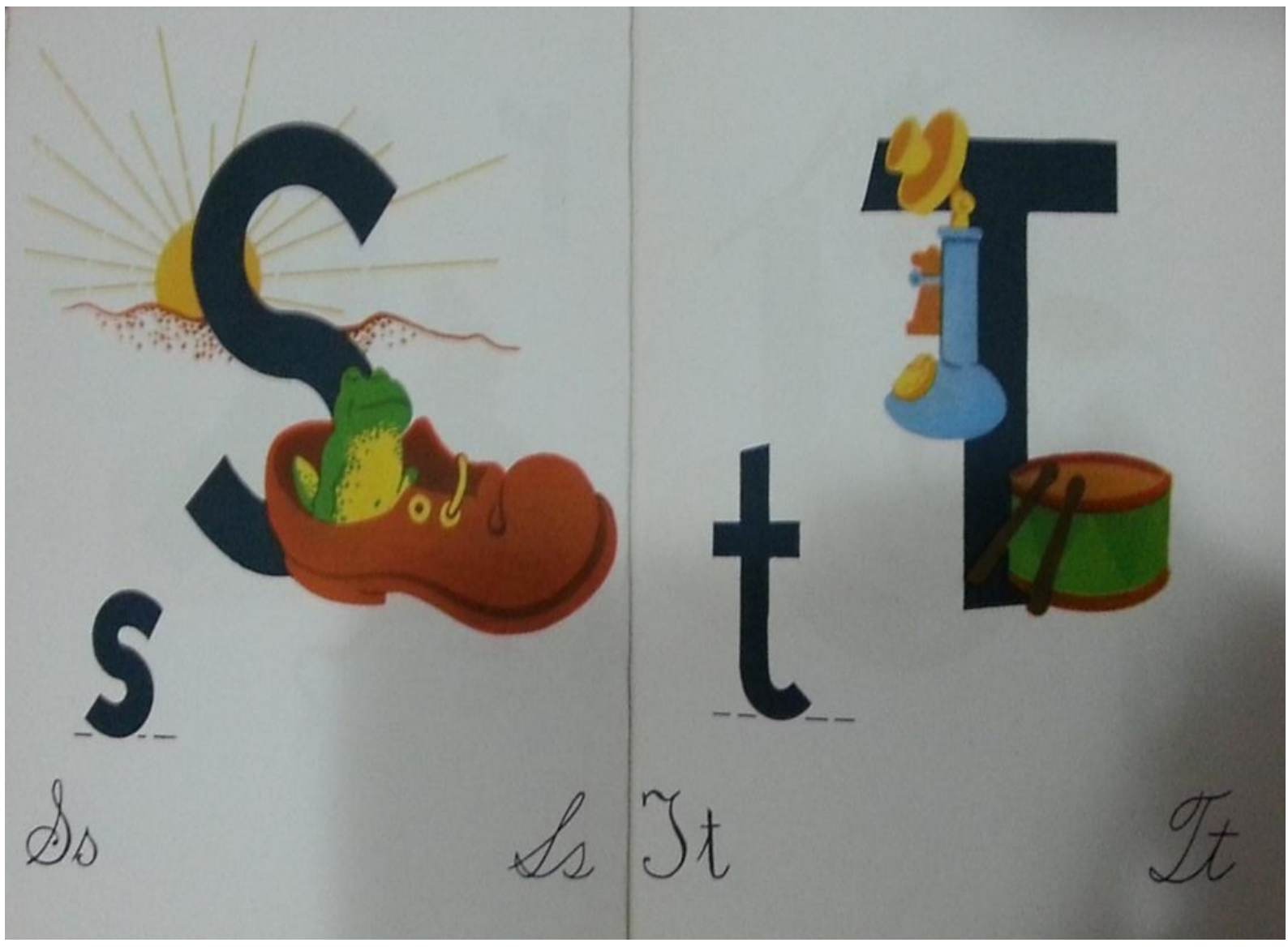

Está organizado de $\mathrm{A}$ a $\mathrm{Z}$ sem a inclusão das letras $\mathrm{K}, \mathrm{X}, \mathrm{Y}, \mathrm{W}$. Apresenta a letra script maiúscula e minúscula em destaque, não havendo o uso de cores diferentes para cada uma delas, como observamos no $A B C$ das aves. Há, também, dois tipos de letra caligráfica em versões maiúscula e minúscula - elemento diferente. Consta, em geral, mais de uma imagem associada à letra e não está escrito o nome das imagens como no abecedário descrito na cartilha precedente. Toda a sequência das páginas segue este padrão, alterando as letras e as imagens a elas associadas.

$\mathrm{Na} 12^{\mathrm{a}}$ edição, do ano de 1965 , observamos apenas uma alteração em relação à $4^{\mathrm{a}}$ edição: em cada página estão acrescidas palavras que designam a ilustração e que estão associadas à letra. 
Figura 16 -

Página da cartilha $M e u A B C$.

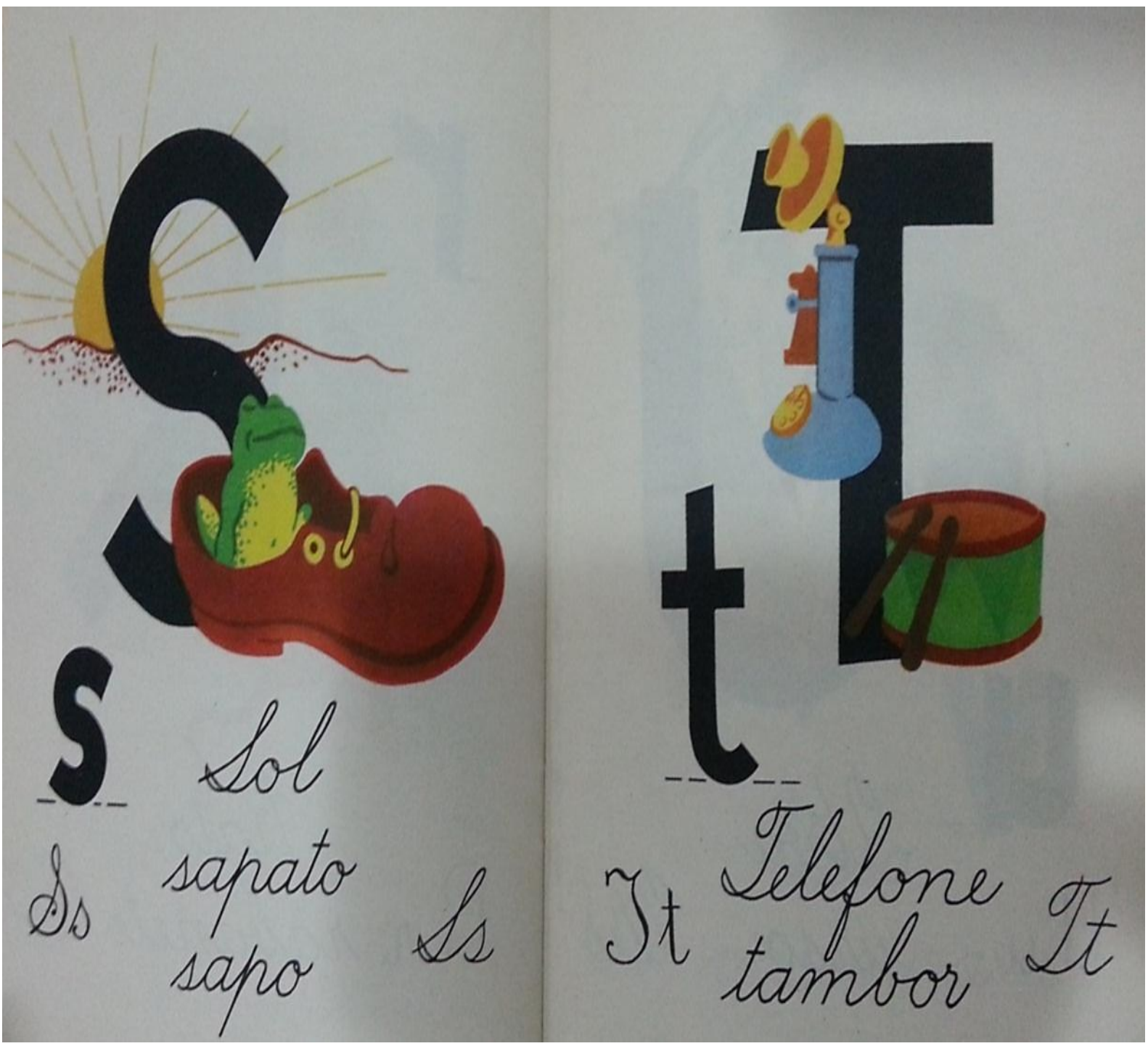

Percebe-se na imagem acima que as palavras foram inscritas somente no tipo de letra caligráfica inclinada - versão da letra localizada no canto inferior direito. Tal observação difere do impresso $O A B C$ das aves, que apresenta o nome da ave também em letra imprensa toda maiúscula.

Sobre o universo temático das ilustrações das cartilhas examinadas, observou-se que a presença de animais foi comum e frequente nesses impressos. No abecedário $\mathrm{Meu}$ $A B C$, as imagens de capa e no interior parecem remeter a elementos/objetos do cotidiano infantil - animais, brinquedos, frutas, hortaliças, instrumentos musicais - como forma de aproximação e identificação com o público leitor. Além disso, o uso do pronome pessoal meu escolhido para integrar o título, corrobora tal entendimento. 
Vale o registro de algo curioso que sucedeu quando nos dispusemos a folhear os impressos que se apresentam como abecedários: constatamos que inexiste a menção ao nome do autor, embora em quase todas as cartilhas exista a menção ao nome do ilustrador:

O abecedário situa os impressores do lado de uma tradição editorial que se apoia nas obras sem autoria, repostas ano após ano, sem a preocupação de inovar, em um domínio no qual a permanência e a perenidade continuam os maiores critérios de uma qualidade que se obtém sem despesas. (Hébrard, 2002, p. 15)

Hébrard refere-se aos abecedários publicados a partir da lógica da Bibliothèque Bleue, na França do século 17. Essa prática editorial apresenta algumas nuances se posta em comparação com a dos abecedários apresentados neste estudo: a autoria indicada nos abecedários do Acervo refere-se à ilustração, com omissão da autoria daquele que pensou sobre os usos dos variados tipos de letra, a inclusão ou não de palavras, ou de frases, etc. Tais aspectos podem estar relacionados ao projeto gráfico, e por isso, supostamente, não haveria necessidade de indicação da autoria dos demais elementos tipográficos do impresso. Parece importante ressaltar que esses aspectos dizem respeito aos usos do abecedário, e se nesse sentido houve uma atenção ao ensino da escrita e à grafia das letras, além de considerar as escolhas pedagógicas e de método adotadas.

\section{Considerações finais}

Procuramos acompanhar alguns momentos e objetos que demonstram a ampla, histórica e diversa circulação do abecedário, artefato que privilegiamos para compreensão de um aspecto fundamental da história da cultura escrita. Nossos propósitos não se esgotaram. No curso da pesquisa documental, outros diversos aspectos e dimensões foram formulados, em especial aqueles associados à didatização específica a que os abecedários estão sujeitos no contexto das cartilhas, em especial se comparados a outros usos e suportes nos quais ele esteve ou está incluso. Por exemplo, esboçamos apenas alguns anúncios da inscrição dos mesmos como instrumentos utilizados para o aprendizado das letras, para fins de escrita artística ou caligráfica, ou como coleção do pitoresco reunido em livros de coleções de curiosidades de viagens.

De outra parte, procuramos apontar alguns dos modos como são desdobrados em diversos manuais, ilustrações, cartilhas ou pranchas e que contemplam diferentes possibilidades de sua grafia: maiúsculas, minúsculas, caligráficas, script, em diferentes idiomas/alfabetos, desenhados, impressos, bordados, esculpidos, etc.

Indiscutivelmente, a inscrição do abecedário na história da alfabetização e, mais amplamente, da escolarização, implica analisá-lo como gênero textual inventado, transmutado para fins escolares, o que merece uma atenção particular. De qualquer forma, há muito por compreender acerca de sua importância e dos transbordamentos da vida sociocultural para a escola, ou os transbordamentos dos dispositivos escolares para outras práticas culturais, como hoje podemos observar nas atividades lúdicas 
experimentadas desde a pequena infância nos suportes digitais, exemplificadas por jogos com letras e palavras em casa, na rua, na praça, nos mais inusitados lugares em que é possível interagir com as mídias eletrônicas, e onde também se pode aprender a leitura e a escrita.

A tradição secular dos abecedários parece resistir a muitas revoluções dos suportes de escrita e leitura, bem como de seus usos sociais e educacionais. Eis que se apresentam, ainda, renovados, e ao mesmo tempo sob uma forma gráfica das mais antigas, que os acompanha desde a sua emergência como dispositivo de acesso à cultura escrita em diferentes tempos.

\section{Referências}

ACERVO MEMÓRIA DA CARTILHA. Disponível em http://www.ufrgs.br/faced/extensao/memoria.

ANDRADE, Tales de. Ler brincando: nova cartilha. 51 ed. São Paulo: Companhia Editora Nacional, 1949.

CAGLIARI, Luis Carlos. A história do alfabeto. São Paulo: Paulistana, 2009.

CAGLIARI, Luis Carlos. Alfabetizando sem o bá-bé-bi-bó-bu. São Paulo: Scipione, 2003.

CARRETE, David; PÉRON, Jacques. Sur les bancs de l'école: les objets de la communale. Paris: Editions du Layeur, 2007.

CHAGAS, Manoel Pinheiro (Dir.). Diccionario popular: historico, geographico, mytologico, biographico, artistico, bibliographico e litterario. $1^{\circ} \mathrm{v}$. Lisboa: Lallemant Frères Typ. , 1876.

CHARTIER, Anne-Marie. Des abécédaires aux méthodes de lecture: gènese du manuel moderne avant les lois Ferry. Mimeo, 2004.

CHOPPIN, Alain. Le manuel scolaire, une fausse evidence historique. Histoire de l'education, Paris, n. 117, 2008, p. 7-56. Disponível em <http://www.cairn.info/article>. Acesso em 3 maio 2013.

CUCUZZA, Héctor Rubem; PINEAU, Pablo (dir.). Para una historia de la enseñanza de la lectura y escritura. Buenos Aires: Miño y Dávila, 2002.

DICIONÁRIO HOUAISS DA LÍNGUA PORTUGUESA. Rio de Janeiro: Objetiva, 2001.

DUVALLON, Jean. Les abécédaires. Paris: De Borée, 2010.

ESCOLANO BENITO, Augustín. Los comienzos de la edición escolar moderna en España. Madrid: Anele, 2000, p. 14-33.

FRADE, Isabel Cristina Alves da Silva Frade. Uma genealogia dos impressos para o ensino da escrita no século 19. Revista Brasileira de História da Educação, n. 44, 2010, p. 264-281.

FREITAS, Altina Rodrigues de. O bom colegial. 17 ed. São Paulo: Francisco Alves, 1948. GAYER, Olga Acauan; SOUZA, Branca Diva Pereira de. Queres ler? Porto Alegre: Selbach, 33 ed., 1919.

HÉBRARD, Jean. Os livros escolares da Bibliothèque Bleue: arcaísmo ou modernidade? Revista Brasileira de História da Educação, n. 4, 2002, p. 10-45.

MEU ABC. Ilustrações de Dorca. São Paulo: Melhoramentos. 4 ed., s/a.

MEU ABC. Ilustrações de Dorca. São Paulo: Melhoramentos. 12 ed., 1965.

MORAIS, Teodoro de. Sei ler: leituras intermediárias. São Paulo: Companhia Editora Nacional, 50 ed., 1949. 
O ABC DAS AVES. Ilustrações de Renato Demonte Ferraz. São Paulo: Melhoramentos. 3 ed., 1965.

SCHWARCZ, Lilia M.; AZEVEDO, Paulo Cesar de. O livro dos livros da real biblioteca. São Paulo: Fundação Odebrecht, 2003.

SOUZA, Mariana Souza Pereira. Abecedários, Brasil: contribuições à história dos impressos e sua circulação nos anos 1936 a 1984. Porto Alegre: Ufrgs, 2015. $152 f$. Dissertação (Mestrado em Educação). Faculdade de Educação, Universidade Federal do Rio Grande do Sul.

STEPHANOU, Maria; SOUZA, Mariana Venafre Pereira. Contribuições para uma história dos métodos didáticos de alfabetização: os abecedários em cartilhas escolares (19191965). SEMINÁRIO INTERNACIONAL SOBRE A HISTÓRIA DO ENSINO DA LEITURA E DA ESCRITA, 2013. Anais ... Belo Horizonte: Sihele/UFMG, 2013.

STEPHANOU, Maria; BASTOS, Maria Helena Camara. Educar a escrita: os sentidos da caligrafia na história da educação. ENCONTRO SUL-RIO-GRANDENSE DE PESQUISADORES EM HISTÓRIA DA EDUCAÇÃO, 14, 2008. Anais ... Pelotas: Asphe, 2008.

TRINDADE, lole Maria Faviero. A invenção de uma nova ordem para as cartilhas: ser maternal, nacional e mestra - Queres ler? Bragança Paulista: USF, 2004.

UFRGS. Biblioteca da Faculdade de Educação. Memória da Cartilha < Disponível em: http://www.ufrgs.br/faced/extensao/memoria/ > acesso em abril de 2013.

VANDER, Pierre Aa. Galerie agréable du monde. In: SCHWARCZ, Lilia M.; AZEVEDO, Paulo Cesar de. O livro dos livros da Real Biblioteca. São Paulo: Fundação Odebrecht, 2003, p. 146.

VINÃO FRAGO, Antonio. Os cadernos escolares como fonte histórica: aspectos metodológicos e historiográficos, In: MIGNOT, Ana Cristina Venâncio (org.). Cadernos à vista: escola, memória e cultura escrita. Rio de Janeiro: Uerj, 2008, p. 15-33.

MARIA STEPHANOU é professora titular na Faculdade de Educação da Universidade Federal do Rio Grande do Sul. Pesquisadora do CNPq, atua junto ao Programa de Pós-Graduação em Educação na linha de pesquisa História, Memória e Educação. Doutora em Educação pela UFRGS, realizou seu pós-doutoramento junto ao Institut Français d'Éducation, IFÉ, França. Atua como co-editora da revista História da Educação desde 2011.

Endereço: Rua Dr. João Palombini, 144A - 91751-150 - Porto Alegre - RS - Brasil.

E-mail: mastephanou@gmail.com.

MARIANA VENAFRE PEREIRA SOUZA é professora na Escola Municipal de Ensino Fundamental Décio Martins Costa onde atua como regente nos anos iniciais do ensino fundamental. É licenciada em Pedagogia pela Universidade Federal do Rio Grande do Sul e mestre em Educação pela mesma Universidade.

Endereço: Rua Rodolfo Herschdorfer, 57 - 91130-690 - Porto Alegre - RS - Brasil.

E-mail: marianavenafre@gmail.com.

Recebido em 22 de janeiro de 2016.

Aceito em 7 de junho de 2016. 